\title{
Completeness of radiosonde humidity observations based on the Integrated Global Radiosonde Archive
}

\author{
António P. Ferreira, Raquel Nieto, and Luis Gimeno \\ Environmental Physics Laboratory, Faculty of Science, University of Vigo, Ourense, 32004, Spain \\ Correspondence: António P. Ferreira (ap.ferreira@uvigo.es)
}

Received: 12 August 2018 - Discussion started: 15 October 2018

Revised: 7 April 2019 - Accepted: 10 April 2019 - Published: 9 May 2019

\begin{abstract}
Radiosonde measurements from the 1930s to present give unique information on the distribution and variability of water vapor in the troposphere. The sounding data from the Integrated Global Radiosonde Archive (IGRA) Version 2 are examined here until the end of 2016, aiming to describe the completeness of humidity observations (simultaneous measurements of pressure, temperature, and humidity) in different times and locations. Upon finding the stations with a non-negligible number of radiosonde observations in their period of record, thus removing pilot-balloon stations from IGRA, the selected set (designated IGRA-RS) comprises 1723 stations, including 1300 WMO stations, of which 178 belong to the current GCOS Upper-Air Network (GUAN) and 16 to the GCOS Reference Upper-Air Network (GRUAN). Completeness of humidity observations for a radiosonde station and a full year is herein defined by five basic parameters: number of humidity soundings, fraction of days with humidity data, average vertical resolution, average atmospheric pressure and altitude at the highest measuring level, and maximum number of consecutive days without data. The observations eligible for calculating precipitable water vapor - i.e., having adequate vertical sampling between the surface and $500 \mathrm{hPa}$ - are particularly studied. The present study presents the global coverage of humidity data and an overall picture of the temporal and vertical completeness parameters over time. This overview indicates that the number of radiosonde stations potentially useful for climate studies involving humidity depends not only on their record length, but also on the continuity, regularity, and vertical sampling of the humidity time series. Additionally, a dataset based on IGRA is described with the purpose of helping climate and environmental scientists to select radiosonde data according to various completeness criteria - even if differences in instrumentation and observing practices require extra attention. This dataset consists of two main subsets: (1) statistical metadata for each IGRA-RS station and year within the period of record; and (2) metadata for individual observations from each station. These are complemented by (3) a list of the stations represented in the whole dataset, along with the observing periods for humidity (relative humidity or dew-point depression) and the corresponding counts of observations. The dataset is to be updated on a 2-year basis, starting in 2019, and is available at https://doi.org/10.5281/zenodo.1332686.
\end{abstract}

\section{Introduction}

For about three-quarters of a century, the global radiosonde network designed and developed for weather forecasting has provided in situ observations of humidity from the surface up the middle troposphere, and eventually reaching the stratosphere. Satellite-based remote sensing of atmospheric water vapor is part of modern weather forecasting and climate monitoring (Kley et al., 2000; Andersson et al., 2007). In the present state of the art, some satellite retrievals of moisture- related quantities are used as a reference to compare humidity measurements from different radiosonde types, aiming to monitor radiosonde stations and improve satellite calibration (Kuo et al., 2005; John and Buehler, 2005; Sun et al., 2010; Moradi et al., 2013). However, limb-sounding satellite techniques with high vertical resolution (albeit very course in the horizontal direction), using GPS radio occultation, are a recent acquisition, of main interest to access water vapor in the upper troposphere and lower stratosphere so far 
(Kishore et al., 2011; Shangguan et al., 2016; Rieckh et al., 2018; Vergados et al., 2018). Reanalysis outputs based on past radiosonde data, also assimilating satellite data when available, offer multiple-level, globally gridded, synopticscale moisture fields up to four times daily from a beginning year (e.g., 1948 in NCEP/NCAR Reanalysis 1; 1979 in NCEP/NCAR Reanalysis 2 and ECMWF's ERA-Interim) to present time - even though radiosonde observations are scarce over the ocean, unevenly spaced over land, and taken normally twice a day, with significant differences in vertical coverage. Naturally, since air moisture is highly variable in time and space, humidity data from different reanalysis models show discrepancies and can differ significantly from the collocated radiosonde data (e.g., Noh et al., 2016). Therefore, the radiosonde archives represent the primary source of information on the short- and long-term distribution of moisture in the troposphere, despite various data inhomogeneities. Namely, geographical and temporal sampling differences (Wallis, 1998), uncertainties related to observation time and balloon drift (Kitchen, 1989b; McGrath et al., 2006; Seidel et al., 2011; Laroche and Sarrazin, 2013), differences in vertical coverage and data gaps related to reporting practices of humidity (Dai et al., 2011, and references therein), and differences in humidity data accuracy - which depend on humidity sensors and vary with measured conditions (WMO, 1995; Nash, 2002; Sapucci et al., 2005; Moradi et al., 2013; Dirksen et al., 2014).

The growth interest in climate change has motivated a renewed attention to radiosonde data since the 1990s. Soon it was realized that the usefulness of radiosonde data archives to investigate climate trends relies on homogenization procedures to overcome biases and sudden shifts arising from instrument changes, reporting practices, and sampling differences (Elliott and Gaffen, 1991; Schwartz and Doswell, 1991; Parker and Cox, 1995; Luers and Eskridge, 1998; Lanzante et al., 2003). Subsequent climate studies based on radiosondes have mostly focused on the detection of climate change in temperature trends (Free and Seidel, 2005; Thorne et al., 2005; Haimberger et al., 2008). Concerning humidity, radiosonde-based climatic studies are for now confined to the lower and middle troposphere because of the large uncertainty of measurements and biases in the upper troposphere and lower stratosphere (Elliot and Gaffen, 1991; Soden and Lanzante, 1996; Wang et al., 2003) and the extremely large relative biases and insufficient data in the lower stratosphere (Miloshevich et al., 2006; Nash et al., 2011). Radiosonde data have been used for studying the long-term trends and the annual cycle of several humidity parameters (precipitable water vapor, specific humidity, and relative humidity), at least in well-sampled regions of the globe and if data inhomogeneities are removed (Elliot et al., 1991; Gaffen et al., 1992; Ross and Elliott, 1996, 2001; McCarthy el al., 2009; Durre et al., 2009; Dai et al., 2011). On a rather different scale, radiosonde measurements with high vertical resolution near the ground are suitable for studying water evapo- ration over land and the structure of the planetary boundary layer, provided that the time lag of humidity sensors as they move through a rapidly changing environment is accounted for (Sugita and Brutsaert, 1991; Connell and Miller, 1995; Seidel et al., 2010).

Since its creation in 2004, the Integrated Global Radiosonde Archive (IGRA) was meant to be the largest dataset of up-to-date weather-balloon observations freely available, by collecting quality-controlled data from upper-air stations across all continents. The first version of IGRA (a successor of the Comprehensive Aerological Reference Data Set CARDS; Eskridge et al., 1995) contained data after 1945 (Durre et al., 2006). IGRA Version 2 used in this paper, released by the NOAA's National Centers for Environmental Information (Durre et al., 2016) and recently described in Durre et al. (2018), has enhanced data coverage and extends back in time as early as 1905, although (for historical reasons) humidity data begin in 1930 with a sole location in Europe. The extension to observations prior to 1946 resulted mainly from the addition of data from the Comprehensive Historical Upper-Air Network (CHUAN), which is the most important collection of upper-air observations taken before 1958 (Stickler et al., 2010). In view of the huge number of data collected in IGRA (which is a combination of radiosonde and pilot-balloon observations) and the differences in the observing period, temporal regularity and continuity, vertical resolution, and vertical extension of humidity data among different stations, finding the most suitable humidityreporting stations (or humidity soundings from different stations) for a specific purpose can be difficult to put into practice.

Radiosonde humidity measurements involve the simultaneous measurements of pressure, temperature, and relative humidity or dew point depression. Therefore, except for horizontal wind, which is indirectly measured with the aid of a remote tracking device, humidity represents the most accomplished of the radiosonde observations. The purpose of this paper is to study the completeness of humidity observations collected in IGRA according to various needs - number and latitudinal distribution of observing stations, fraction of observing days in a year, resolution and range of vertical levels, length and continuity of the time series, minimal sampling between the surface and the $500 \mathrm{hPa}$ level - aiming to facilitate the use of radiosonde humidity data by atmospheric and environmental scientists. The task is twofold: first, to elucidate the completeness of the humidity observations from IGRA for each year in global terms, including the latitudinal coverage of stations and the length of regular time series; second, to provide metadata describing the completeness of humidity observations from each station. The observing periods without missing years in humidity data must be clarified. Latitudinal and regional differences should be easily derived from the geographic coordinates of stations.

The remainder of this section is intended to clarify the term "completeness of observations" concerning the use of 
radiosonde data and to present a historical account of the main factors that limit the completeness of humidity observations from radiosondes: vertical levels available in radiosonde reports and missing observations associated with humidity sensor limitations. The next sections are organized as follows. Section 2 indicates the IGRA dataset used in the study, selects the IGRA stations reporting a minimum of radiosonde data (coined "IGRA-RS") by discharging stations with practically wind-only data in their period of record, and explains the data analysis. Section 3 presents a global picture of the completeness of humidity observations over the years, as derived from the IGRA-RS stations. Section 4 provides the definition of the metadata parameters describing the completeness of humidity observations from each IGRA-RS station - either as annual statistics or for individual soundings - and the format description of the corresponding datasets. The availability of the resulting dataset (Ferreira et al., 2018) is reported in Sect. 5. A summary of results and some suggestions for future application are given in Sect. 6.

\subsection{Completeness of observations for radiosonde humidity studies}

Data completeness in a dataset refers to the extent to which the dataset collects the expected elements: quality-assured data are not left out; missing or invalid values are properly indicated. This is a basic requirement for data quality, and it is assured in IGRA. In a different way, and uncommonly, data completeness may refer to whether the required data for a specific purpose are available or not. That meaning is not new in the field of meteorology. For instance, the WMO recommendations on "data completeness" (sic) required for calculating monthly means and climate normals from meteorological surface data refer to the temporal continuity and regularity of observations for different climate elements (WMO, 1989). Broadly, Bellamy (1970) discussed the acceptability of meteorological observations in terms of their degree of completeness, considering that the goal of meteorological observations is to "depict the space-time distributions of everything-atmospheric everywhere always, ever more completely in ever-increasing detail"; appropriately, he used the expression completeness of observations. This is the terminology used in the present paper.

Concerning the completeness of radiosonde humidity observations, the vertical coverage and vertical resolution of sounding data are of first concern, chiefly between the surface and the middle troposphere $(\sim 500 \mathrm{hPa})$ regarding the precipitable water vapor content; furthermore, the period of record and the regularity and continuity of radiosonde data are relevant issues for long-term monitoring of the climate system (Karl et al., 1995), as exemplified by temporal sampling requirements used in trend and seasonal analysis of temperature, humidity, and integrated water vapor (Gaffen et al., 1991; Gaffen et al., 1992; Karl et al., 1995; Ross and Elliot, 1996; Zhai and Eskridge 1997; Lanzante et al., 2003;
McCarthy et al., 2009). Although the vertical and temporal completeness of station-based humidity time series can be treated separately from the geographical coverage of stations, studying the completeness of observations in a global, historical dataset of radiosonde observations should address both issues simultaneously. This is particularly true concerning the subsampling of radiosonde stations for studies of atmospheric temperature or water vapor trends on a regional or global scale (Wallis, 1998).

Several factors contribute to differences in the completeness of humidity observations among radiosonde stations and individual soundings: (i) the geographical coverage of radiosonde stations evolved over time, and so the period of usage varies among stations; (ii) a lack of equipment maintenance may result in interruptions of observations; (iii) the number of vertical levels and the vertical extent in radiosonde reports depend on the standard pressure levels in use, as well as on the reported significant levels (assuming that the balloon bursts at the proper altitude); (iv) missing humidity data in all or part of the reported levels arise from difficulties associated with the performance of humidity sensors and the observing practices related to their working range. While (i) and (ii) are of a random nature, points (iii) and (iv) deserve an explanation because of historical changes with implications in the vertical coverage and resolution of radiosonde humidity profiles.

\subsection{Vertical levels in radiosonde observations}

In radiosonde soundings, temperature, relative humidity (and/or dew point depression), and wind speed and direction are measured together with atmospheric pressure, while geopotential height is indirectly measured from hypsometric calculations ${ }^{1}$ (but may be missing in radiosonde reports). As a common practice, only standard pressure levels and significant levels are stored and reported. Currently, the standard levels are 1000, 925, 850, 700, 500, 400, 300, 250, 200, 150, 100, 70, 50, 30, 20, and $10 \mathrm{hPa}$ (WMO, 1996). But historical changes deserve due attention. An inspection of the earliest soundings collected in IGRA - made in 1905 at Lindenberg, Germany, a quarter of a century before radiosondes were available - reveals temperature data reaching sometimes $100 \mathrm{hPa}$, with the reported levels being 1000,925 , $850,700,600,500,400,300,250,200,150$, and $100 \mathrm{hPa}$ (although most of those soundings did not reach beyond $700 \mathrm{hPa}$ ). Radiosonde humidity measurements at the same station, as collected in IGRA, began in 1950. Nevertheless, the 150 and $100 \mathrm{hPa}$ levels were first recommended by the WMO in 1953, while the levels 70,50,30, 20, and $10 \mathrm{hPa}$ were proposed in 1957, the International Geophysical Year.

\footnotetext{
${ }^{1}$ Except in some Soviet/Russian radiosonde-radar systems and the last generation of GPS radiosondes - in which pressure is deduced from the (radar or GPS, respectively) profile of geometric height and the radiosonde profiles of temperature and humidity (Zaitseva, 1993; Nash et al., 2011).
} 
Even so, the levels above $200 \mathrm{hPa}$ were still referred to as nonstandard by the WMO in 1958 , until the $100 \mathrm{hPa}$ level was finally adopted that year (WMO, 1957, 1958). In the years that followed, the pressure levels $\leq 150 \mathrm{hPa}$ (representing roughly the stratosphere) became common worldwide. As for the lower levels $\geq 200 \mathrm{hPa}$ (representing roughly the troposphere), they were in general use since the early 1940s, with two exceptions: first, the $250 \mathrm{hPa}$ level was only adopted in 1970, to satisfy aviation demands (WMO, 1970); second, the $925 \mathrm{hPa}$ level (within the planetary boundary layer above low-altitude stations), although planned since 1977, was first required in WMO Antarctic stations in 1987, given the low surface pressure over the Antarctic Plateau, until it was adopted worldwide by the end of 1991 (WMO, 1977, p. 15; WMO, 1987, pp. 57-58; Oakley, 1993, p. 23). Note, however, that these two levels were in use in some stations before international agreement, and for a long time as exemplified by the Lindenberg station. In addition to the standard levels, some intermediate fixed levels within the troposphere (e.g., 800, 750, 650, 600 hPa) were regularly used at some stations (Shea et al., 1994). The Lindenberg station indicates the early use of $600 \mathrm{hPa}$. The additional (high-stratospheric) levels $7,5,3,2$, and $1 \mathrm{hPa}$ have been used for decades in agreement with WMO recommendations (WMO, 1970), depending however on regional and national practices; e.g., they form part of "upper-level" observations in the US National Weather Service (OFCM, 1997).

The number of significant levels - nonstandard levels needed to reproduce the vertical temperature and dewpoint temperature profiles, capturing turning points or abrupt changes (such as thermal inversions and the tropopause) depend on atmospheric conditions, manual rules, and, before automation, on the observers' skills. By the late 1950s, the rules for choosing significative levels were still under discussion (WMO, 1957), being established over time by WMO regulations (WMO, 1988). Interestingly, the almost linear increase in the average number of nonstandard levels in weather-balloon sounding reports (radiosondes + pilot balloons) from about zero by 1945 to about 30 by 2000 - as revealed from IGRA v1, inferring from Fig. 7 in Durre et al. (2006) - can hardly be attributed to an increased attention to significant levels alone. It suggests that a significant number of stations have reported additional levels apart from the standard and significant levels (both "mandatory" in WMO's nomenclature).

The surface level, which is treated separately in upper-air sounding reports, has been reported at most of the radiosonde stations since the mid-1940s. However, it has been reported systematically only since around 2000 (as shown later in Sect. 2.3).

The current migration of radiosonde reports from alphanumeric (TEMP) to the binary universal form for the representation of meteorological data (BUFR), together with the conversion of radiosondes to generate native BUFR messages, allows the transmission of high-resolution data (2 to $10 \mathrm{~s}$ sampling rate, i.e., $\sim 5$ to $50 \mathrm{~m}$ resolution in a typical balloon ascent) along with the balloon drift position, the observation time for each level, and other metadata (Ingleby et al., 2016). Currently, $20 \%$ of the radiosonde stations send highresolution BUFR reports through the Global Telecommunication System (GTS), many coming from Europe; however, such data are not yet available in an open archive.

\subsection{Missing humidity observations}

Combining adequate spatial and temporal resolution with enough accuracy for synoptic use, modern radiosonde measurements reach the upper troposphere and lower stratosphere, much beyond the layers where most of the atmospheric water vapor resides. That has not always been so. While the vertical sampling of temperature observations is limited by the burst altitude and the mandatory levels (standard and significant), the maximum height and the vertical resolution of humidity observations are further restricted by sensor limitations. Upper-air humidity measurements began in the 1930s but became substantial only in the 1940s. Despite radiosonde hygrometers (measuring relative humidity, $\mathrm{RH}$ ) having improved over time, humidity has always been difficult to measure in very cold or dry air due to the poor response of many instruments at very small vapor concentrations (by lowering saturation vapor pressure, cold temperatures are associated with low water vapor pressures). As it was once pointed out, "humidity measurements in the free atmosphere are probably the least satisfactory of the regular aerological observations" (Hawson, 1970). Balloon-based chilled mirror hygrometers, designed to measure water vapor mixing ratios in the stratosphere (an extremely cold and dry environment), have been used for more than half a century but are exclusive to scientific research or comparison with humidity measurements from operational radiosondes (Mastenbrook and Daniels, 1980; Vömel et al., 2007; Hurst et al., 2011; Hall et al., 2016). Since a long time ago, weather services have needed to rely on meteorological radiosondes consisting of expandable balloons carrying relatively low-cost and light instrument packages (Brettle and Galvin, 2003).

Here is a brief review of the main humidity sensor types and their limitations, since the time when registering balloons were abandoned by national weather services and electric hygrometers began to be incorporated in radiosondes (circa 1940; DuBois et al., 2002). The lithium chloride humidity sensors, which were widely used in radiosondes between the mid-1940s and the mid-1960s, did not respond to temperatures below around $-40^{\circ} \mathrm{C}$. From the early $1960 \mathrm{~s}$ onwards, the new carbon hygristor allowed measurements at lower temperatures - down to $-65^{\circ} \mathrm{C}$ in the early $1990 \mathrm{~s}$, however with a time lag in the sensor's response as large as 10 min (Garand et al., 1992). In practice, humidity measurements at temperatures below $-40{ }^{\circ} \mathrm{C}$ were discontinued in many countries before the $1990 \mathrm{~s}$, limiting the vertical extent of routine humidity observations to about $400 \mathrm{hPa}(\approx 7 \mathrm{~km}$ 
in altitude) (Gutnick, 1962; Gaffen, 1993). Besides, the radiosondes using lithium chloride hygrometers suffered from a low-frequency limitation in the transmission of RH less than $15 \%-20 \%$, known as motorboating (Wade, 1994). The radiosondes using the carbon hygristor enabled, in principle, measurements in that low RH region - however, the accuracy and reproducibility of low-RH values was little known and suspected to be poor for many years, giving the wrong impression that relative humidity lower than about $20 \%$ did not occur in the lower troposphere (Wade, 1994; Nash, 2015). Therefore, values of RH below $20 \%$ were usually cut off in humidity reports; in the radiosonde network of the US this happened between 1973 and 1992 (Elliott and Gaffen, 1991). Note that changes in instrument and reporting practices in different countries took place at different times: the threshold value of RH varied in the range of $10 \%-20 \%$; the lowest temperature of $-40{ }^{\circ} \mathrm{C}$ for reporting humidity, and the shift to lower temperatures, was applied in different periods depending on country; humidity could be reported up to a specified pressure level. Moreover, mechanical sensors are not exclusive to pre-1940s radiosondes: hair hygrometers were only abandoned in the mid-1950s and rolled hair hygrometers were used in a few places until about 1980; the goldbeater's skin sensors introduced in the 1950s became particularly important in the Soviet Union. (For a historical report on changes in radiosonde instruments and practices from the 1930s to the early 1990s, see Gaffen (1993).) The capacitive thin-film sensors introduced in 1981, with the RS80 radiosonde, have improved the response time at low temperatures and the capability of measuring very low humidity. Two important enhancements occurred in the late 1990s. First, a protection from chemical contamination due to outgassing of RS80 radiosonde packages was designed, thus making the dielectric polymer more selective to water vapor molecules and reducing dry bias (Wang et al., 2002). Second, dual sensors were introduced in the RS90 radiosonde, in which two sensors were alternately heated to remove condensation from the measuring sensor, thus preventing wet biases after measurements in saturated conditions. In the RS92 radiosonde, in use since 2004, the lowest temperature of the heating cycle extended down from -40 to $-60{ }^{\circ} \mathrm{C}$. The smaller size and the better ventilation of the RS90 and RS92 sensors compared to RS80 improved the response time. However, RS80 sondes were less affected by dry biases in daytime measurements because of the protective rain cap, which also prevented direct sunlight (Smit et al., 2013). However, RH reports at temperatures lower than $-40^{\circ} \mathrm{C}$ did not develop significantly until about 2000; in recent years, for temperatures of -50 to $-70^{\circ} \mathrm{C}$ only the newest humidity sensors respond quickly enough to make useful measurements; moreover, the best ones had an uncertainty of around $16 \% \mathrm{RH}$ at temperatures as low as $-70^{\circ} \mathrm{C}$ (occurring over Antarctica and around the tropical tropopause), which is barely acceptable for numerical weather prevision but not suitable for climatic studies (Nash, 2015). Improvements over time were not only re- stricted to sensor type but also to data reduction and calibration. For example, measurements from the carbon hygristor in VIZ radiosondes were improved in the 1990s by correcting the low-humidity algorithm; some modern radiosonde systems apply corrections for slow time constant of response and for daytime heating of the humidity sensor; calibration at low temperatures was perfected (Dirksen et al., 2014 and references therein). While radiosonde humidity measurements are now generally reliable in the troposphere, uncertainties remain concerning the upper troposphere, where temperatures can fall below $-50^{\circ} \mathrm{C}$, in addition to dry conditions found above the lower troposphere and wet conditions that occur in thick clouds (Miloshevich et al., 2006). Although the capacitive thin-film sensors have become widespread (with Vaisala radiosondes RS80 and RS92), two older sensor types continued in use for many years: the carbon hygristor (in VIZ/Sippican radiosondes, currently in disuse, and in the GTS1 radiosonde, in use in China) and the goldbeater's skin sensor used in some radiosonde types made in Russia and China until a few years ago; this peculiar sensor responded too slowly to be useful at temperatures lower than $-20^{\circ} \mathrm{C}$ and suffered from hysteresis following exposure to low humidity (Nash, 2015; Moradi et al., 2013). For the current radiosonde types, see Ingleby (2017).

The trouble in measuring upper-air humidity affects the completeness of observations in several ways: the vertical extent of humidity soundings varies much among radiosonde stations and over time owing to sensor limitations in very cold air; vertical gaps in low-humidity regions are expected, due to cutoff of RH below sensors' measuring capability; likewise, missing days in radiosonde humidity records may originate from adverse conditions (dry days, wet days, cold days) at individual stations (Garand et al., 1992; Ross and Elliott, 1996; McCarthy et al., 2009; Dai et al., 2011). As explained above, the actual extent of missing data depends on the observing practices combined with sensor limitations. In addition, failures in some part of the radiosonde system can compromise soundings. Faulty ground equipment used for control checks (sensors' calibration before balloon release), data reduction, and data recording or telecommunication of coded reports may cause long inoperative periods; poor signal reception from the radiosonde sometimes make data processing impossible. Radiosonde operations in remote environments, particularly performed from ships, present their own challenges; Hartten et al. (2018) give a vivid illustration. In sum, the vertical extent, vertical resolution, temporal regularity, and continuity of humidity reports are quite heterogeneous.

\section{Input data and methods}

We have examined the IGRA 2 main dataset until the end of 2016. Section 2.1 briefly presents that dataset, including the quality assurance of humidity data. Section 2.2 provides 
a first look at the data, to find out how many and which of the IGRA stations have a non-negligible number of radiosonde observations (RAOBs), and at the same time to give a hint of the number of humidity observations. Section 2.3 describes the data analysis, aiming to explore the completeness of humidity observations in the sense introduced in Sect. 1.

\subsection{IGRA 2 - sounding data}

The IGRA 2 consists primarily of radiosonde ${ }^{2}$ and pilotballoon $^{3}$ observations from over 2700 globally and temporally distributed stations, even though the coverage over oceans is limited to islands, ships, and buoys. This paper is concerned with sounding data (Durre et al., 2016), comprising over 45 million soundings from 2761 (2662 fixed and 99 mobile) stations (based on data accessed in September 2017).

The main difference between IGRA 2 and IGRA 1 is the number of sounding data: 33 data sources instead of the initial 11, implying about $80 \%$ more stations; new data from hundreds of stations before 1946; and the addition of floating stations (fixed weather ships and buoys, mobile ships, and Russian ice islands); furthermore, humidity data prior to 1969 were added. The latter change is related to how humidity values were stored in radiosonde reports. Until 1969, humidity observations were given only as RH; since then, $\mathrm{RH}$ measurements have normally been converted to dew point depression (DPD) and reported mostly in that form. Different assumptions in the conversion code can lead to inconsistencies in data (Garand el al., 1992). The former IGRA contained only DPD, while IGRA 2 contains humidity data in either form, as available in original reports, provided they pass the following conditions:

i. data completeness: valid temperature accompanies humidity data;

ii. valid range: $0 \%-100 \%$ for $\mathrm{RH} ; 0$ to $70^{\circ} \mathrm{C}$ for DPD;

iii. internal consistency: DPD-derived RH differs from reported RH by $10 \%$ at most;

\footnotetext{
${ }^{2}$ In modern usage, the term radiosonde refers not only to the early radiosondes but also to the rawindsondes (in use since the 1950s), which, besides measuring thermodynamic parameters, provide wind information with the aid of a radio-theodolite, a radar device, a radio navigation system, or, more recently, GPS (Dabberdt et al., 2002; Nash et al., 2007). Observations from either radiosonde type are often abbreviated as "raob" in meteorological jargon.

${ }^{3}$ Free balloon tracked by optical theodolites or radar to measure upper-air winds (Wenstrom, 1937; Hickman, 2015). Often abbreviated as "pibal". The common single theodolite technique requires the approximate ascent rate to obtain position, while the doubletheodolite method allows a pure trigonometric calculation. In visual tracking, rarely used today but still important where radar tracking or wind measurements from a rawindsonde is not possible, a flashlight is used during night or twilight hours.
}

iv. plausibility: (derived water vapor pressure) $\leq 0.1 \times$ (atmospheric pressure).

Quality checks (i)-(ii), save for the RH range, were integral to IGRA 1 (Durre et al., 2006); check (ii) for RH (with the later introduction of this variable in the archive) and checks (iii)-(iv) were added in IGRA 2 (Durre, 2016; Durre et al., 2018). Note that a RAOB message must have at least temperature data at several pressure levels, while humidity or wind data may be missing, and geopotential height is not always given. The recording of pressure levels, and consistence between pressure and geopotential height whenever the latter is reported in source data, has been assured in IGRA since its first version. IGRA uses a consistent data format, irrespective of the provenience of the data (PIBAL or RAOB). Therefore, RAOBs in IGRA (as well as in situ observations from the pre-radiosonde era) can be simply identified by the presence of temperature data. Wind observations from pilot balloons (PIBAL) have only wind data at several geopotential heights (adjusted from geometrical height measurements and the gravitational field). Concerning humidity data, the precision and accuracy of RH and DPD data vary substantially as a function of RH and temperature, degrading in dry or cold conditions to a greater or lesser extent depending on the radiosonde type (for a review on the subject, see Smit et al., 2013). The information about instrument changes (stations' history), whenever available, is provided in a separate metadata file in IGRA 2 (update of the metadata given in the first version of IGRA, which were mostly taken from Gaffen (1996)).

The most frequent nominal observation times are 03:00 and 15:00 UT until 1957 and 00:00 and 12:00 UT afterwards, which reflects the shift in observing time that occurred in 1957 in major WMO radiosonde networks. In the beginning of 1958 the primary standard hours of WMO upper-air observations were already 00:00 and 12:00 GMT (WMO, 1958). However, in some countries, different synoptic hours were practiced over the years; sometimes stations have performed up to four soundings per day for certain demands (see Gaffen, 1993).

For a description of data coverage and data sources of IGRA 2, a full description of quality assurance of data, and further details on the differences between IGRA 1 and IGRA 2, the reader should see Durre et al. (2018) published after the initial draft of this paper was written. Hereafter, IGRA 2 is simply referred to as IGRA, unless stated otherwise.

\subsection{Identification of radiosonde stations}

The examination of the IGRA reveals that 958 stations have wind-only observations in their full period of record, i.e., $34.7 \%$ of the stations represented in the entire archive. These stations form part of the global pilot-balloon (PIBAL) station network, which evolved over time. As for the rest of 
the stations, some of them changed from a PIBAL launching site to a radiosonde launching site at some point in their period of record - meaning that they are not, strictly, PIBAL stations nor radiosonde stations. Obviously, the number of PIBAL stations or radiosonde stations at a certain time depends on the stations opened and closed before that time, of either type. In the following, terms like "observations", "soundings", or "reports" refer to IGRA data, which retain the vast majority of the source data (Durre et al., 2018).

Figure 1a shows the yearly number of stations reporting RAOBs any time of the year - meaning they have at least observations of temperature, regardless of simultaneous humidity/wind observations - and of stations reporting PIBAL observations alone - i.e., reporting only wind throughout the year. For comparison, the number of stations reporting any humidity data and reporting humidity observations in more than $95 \%$ of the RAOBs is also shown. Constituting the bulk of the IGRA stations until the early 1940s, the stations with only PIBAL data today represent only $13 \%$ of the total. The reason for the apparent discontinuity in the number of stations performing only PIBAL observations between 1972 and 1973 is as follows: beginning in 1973, IGRA data largely come from the GTS and include many more PIBAL data than prior data sources (Imke Durre ${ }^{4}$, personal communication, 12 April 2018). The number of stations reporting RAOBs has increased rapidly since the mid-1940s, staying in the range of 800-900 from around 1970 to present (2016). Note that, before the advent of the radiosonde, upper-air measurements of temperature and relative humidity were made using kites, registering balloons and aircrafts; these platforms were gradually abandoned until the radiosonde era was established in the mid-1940s (DuBois et al., 2002; Stickler et al., 2010). Since the first radiosonde prototypes were developed between 1929 and 1930, the early observations of temperature collected in IGRA, beginning with one station in 1905 (Lindenberg, Germany), were made by meteographs without radiotelemetry. The first upper-air humidity observations are from 1930, coming from a single station: Kjeller, Norway. According to IGRA, until 1942 there were less than 10 stations reporting humidity, with that number growing rapidly in the following years together with the total number of radiosonde stations, reflecting the widespread use of radiosondes (see "HUM" and "TEMP" in Fig. 1a). The major relative change occurred between 1945 and 1946, coincident with the end of World War II, when the global count of radiosonde stations tripled. Note that the replacement of hair hygrometers by the lithium chloride humidity element began in some radiosonde networks shortly before; in the US, apparently that change took place between 1940 and 1943 (Elliott and Gaffen, 1991; DuBois et al., 2002), although IGRA does not contain humidity data from that country prior to 1946. Figure 1a shows also that the fraction of radiosonde stations

\footnotetext{
${ }^{4}$ Center for Weather and Climate, NOAA's National Centers for Environmental Information, Asheville, NC.
}

measuring humidity in more than $95 \%$ of the soundings increased over the years, getting very close to $100 \%$ in the last decade (see relative difference between the curves "TEMP" and "HUM > $95 \%$ ").

Figure $1 \mathrm{~b}$ shows the evolution of the global, annual mean number of observations per day for each atmospheric parameter apart from pressure: temperature, humidity, and wind. Recall that pressure is always measured in RAOB soundings, while in PIBAL soundings wind is measured as a function of altitude $^{5}$. For clarity, the PIBAL wind soundings are depicted separately from all wind measurements, which also comes from RAOB soundings since the mid-1940s. Although, as a rule, radiosonde launches are carried out twice a day, in fact there is a significant number of missing days in temperature and humidity data, i.e., days without any RAOB data: roughly 1 in $5 \mathrm{~d}$ during the year, on average for the years after the mid-1950s (as concluded by comparing the yearly number of observing stations (TEMP, HUM in Fig. 1a) with half the global number of daily observations; TEMP, HUM, in Fig. 1b).

Aiming to study humidity completeness, the IGRA stations having a negligible number of temperature observations in every year of their period of record were excluded because temperature is required to measure RH or DPD and so all humidity data in IGRA are accompanied by temperature data. Specifically, we have selected the stations with RAOB soundings in $5 \%$ or more of the annual soundings in at least one calendar year within their full period of record until the end of 2016. These will be hereafter referred to as IGRA-RS stations (RS stands for radiosonde), even if some of them contribute with relatively few RAOB data. The above selection reduces the number of IGRA stations by $38 \%$, whereas the number of soundings is only reduced by $13 \%$, amounting to 39.5 million, out of which there are 30.2 million RAOBs including 29.8 million humidity observations (see Table 1; Fig. $1 \mathrm{~b}$ shows that the non-PIBAL observations from the pre-radiosonde era are negligible compared to the total number of true RAOBs). Wind-only soundings are still present in $23.6 \%$ of the soundings from the selected stations. Note, however, that $92.2 \%$ of the removed stations are strictly PIBAL stations and the remaining $7.8 \%$ have RAOB data in less than $0.6 \%$ of the corresponding soundings, apart from two cases with a period of record shorter than 1 year. In sum, the IGRA-RS subset retains practically all the RAOB soundings $(99.999 \%)$, particularly the humidity soundings, as shown in Table 1.

The IGRA-RS stations and their locations are listed in Table S1 in the Supplement, along with the full periods of record (Full POR), the periods of record for humidity (Hum POR), and the corresponding numbers of humidity observa-

\footnotetext{
${ }^{5}$ Pressure levels are present in the wind-only data coming from 28 IGRA stations (standard levels with missing height), indicating that an onboard pressure sensor with a radio transmitter was used along with the wind-finding system.
} 

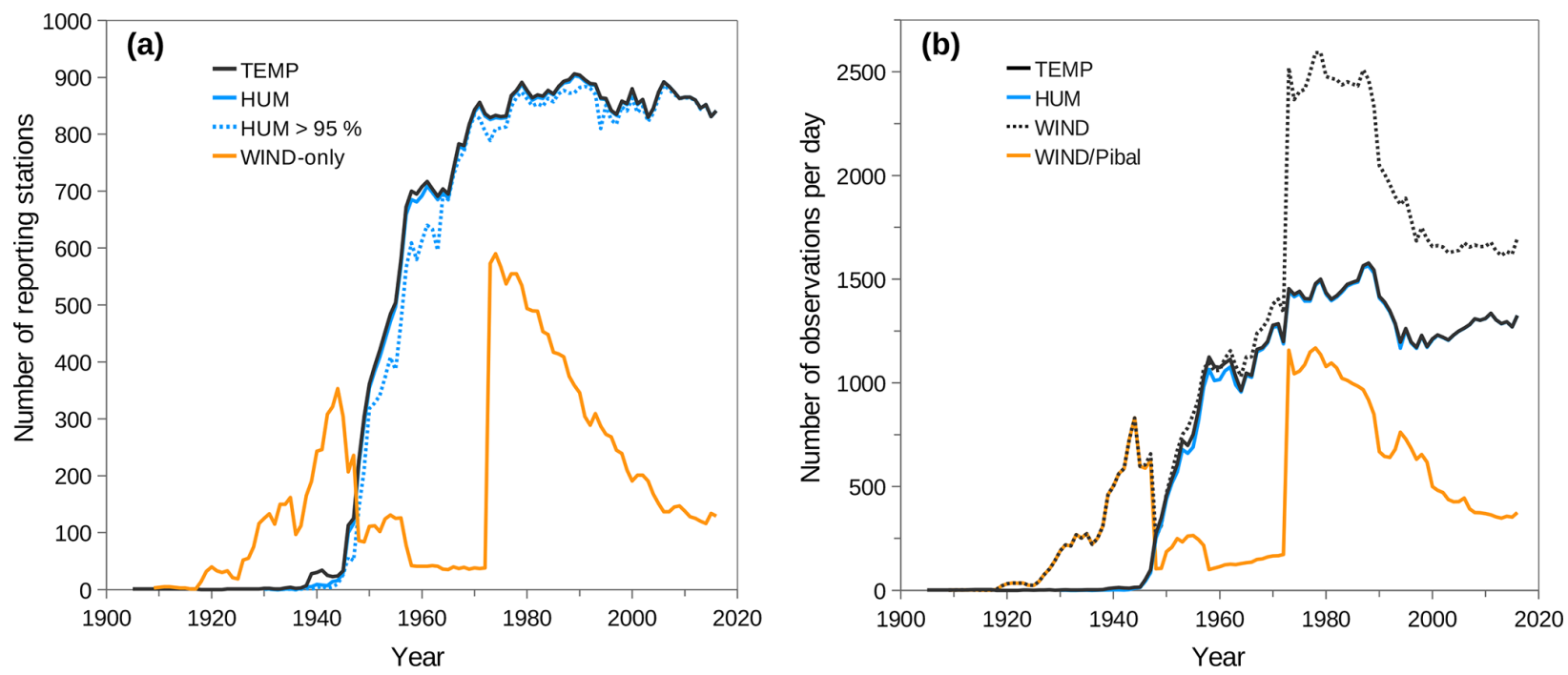

Figure 1. (a) Number of IGRA stations, for each year until 2016, reporting temperature observations, regardless of humidity and wind (TEMP); temperature and humidity observations, regardless of wind (HUM); humidity in at least $95 \%$ of the RAOBs (HUM > 95\%); only wind observations (WIND-only). (b) Yearly average number of observations per day compiled in IGRA, by atmospheric parameter: temperature (TEMP); humidity (HUM); wind from radiosonde or pilot-balloon measurements (WIND); wind from pilot balloons (WIND/Pibal). Note: in panel (a), the sum TEMP + WIND-only gives the global number of stations with any data in IGRA.

Table 1. Number of soundings in IGRA and IGRA-RS subset until the end of 2016 .

\begin{tabular}{lrr}
\hline & $\begin{array}{r}\text { IGRA } \\
(2761 \text { stations })\end{array}$ & $\begin{array}{r}\text { IGRA-RS } \\
(1723 \text { stations })\end{array}$ \\
\hline Total (PIBAL + RAOB) & 45677409 & 39526638 \\
PIBAL (wind-only data) & 15463235 & 9312891 \\
RAOB & 30214174 & 30213747 \\
RAOB with humidity data & 29801708 & 29801324 \\
\hline
\end{tabular}

Note: Pre-radiosonde, non-PIBAL observations are counted as RAOBs.

tions (Hum Obs), i.e., the number of individual soundings reporting either DPD or RH data. Since humidity time series can be interrupted for long periods of time, the full period of record of one station may be segmented into two or more periods for humidity (both are rounded to years). Table S1 comprises 1723 stations, of which 1300 are WMO stations (denoted by the letter "M" following the two-character country code of IGRA identifier codes). Note that in the data from around 120 land stations the early years of record for humidity (normally 2 to 3 years) contain only surface or nearsurface data; this happens at about 100 stations of the former Soviet Union, mostly during the years 1946-1949.

Focusing on the usefulness for climatic studies, the subset of WMO upper-air stations integrated into the Global Climate Observing System (GCOS), i.e., the GCOS Upper-Air Network (GUAN), deserves attention. Formally established in the 1990s, the GUAN was aimed at providing long-term, consistent, homogeneous, and reliable observations needed to monitor the atmospheric component of the global climate system (WMO, 2002; McCarthy, 2008). At present the GUAN comprises 178 stations, all of which are represented in IGRA-RS. The IGRA-derived statistics of humidity observations from the GUAN stations for the period 1 October 2001 to 31 December 2016 are shown in Table S2 in the Supplement, as explained next. "Hum POR" indicates the years with any humidity data in the year, as found in IGRA, but beginning at the time when each station was included in GUAN, or, at least, at the earliest time for which performance indicators for the GUAN stations are available through the NOAA National Centers for Environmental Information website; this is the first day of the month of "begin date" indicated in Table S2. "\# days" is the number of days in Hum POR, excluding the months before begin date. The last three columns give the corresponding count of humidity observations around the principal nominal hours, 00:00 and 12:00 UT $( \pm 1 \mathrm{~h})$, and at any other times (02:00 through 10:00 UT and 14:00 through 22:00 UT). Stations are identified by the WMO region and WMO number, followed by the station name and country. (To find out the corresponding IGRA ID codes in Table S1 it suffices to observe that the last nine characters must be "M000" followed by the WMO number.) Note that most of the GUAN stations have humidity data at or around 00:00 and 12:00 UT almost every day; however, the exceptions to the rule, and even gap years, are not negligible.

Moreover, the IGRA-RS contains 16 stations that form part of the GCOS Reference Upper-Air Network (GRUAN; Bodeker et al., 2016): half certified and half to be certified according to current GRUAN status, of which eight (half cer- 
tified too) are also GUAN stations. Those specific GRUAN sites report default data (from radiosonde manufacturers) to the GTS; at present, most of them already send BUFR messages with high resolution (Michael Sommer ${ }^{6}$, personal communication, 18 September 2018). The GRUAN aims to serve as a reference network for climate applications and satellite validation and in support of other radiosonde networks by providing long-term high-quality records of vertical profiles of selected essential climate variables, accompanied by traceable estimates of measurement uncertainties (WMO, 2011a; Dirksen et al., 2014). Naturally, real-time meteorological data transmitted from GRUAN sites to the GTS may differ from GRUAN internal data regarding raw data processing. For reference, the IGRA ID codes of the GRUAN sites appearing in the IGRA-RS station list are underlined in Table S1; of course, other GRUAN sites performing only research measurements are not part of IGRA. Likewise, the WMO numbers of the GUAN stations coincident with GRUAN sites are underlined in Table S2.

\subsection{Analysis of humidity data}

Overall, the analysis of data from IGRA-RS stations, selected as described in the previous section, aims to answer the following questions:

1. What is the spatial coverage of humidity-reporting stations in different latitudes and years?

2. What is the fraction of days in a year with humidity data and the number of consecutive missing days on average?

3. What is the typical vertical resolution and vertical extent of humidity observations?

4. How many stations have enough data in the vertical direction to allow the estimation of precipitable water?

5. How does the temporal and vertical completeness affect the availability of long-term humidity time series?

Each question is explored as detailed below in Sect. 2.3.12.3.5, with the results presented later in Sect. 3. The description of the related metadata parameters regarding each IGRA-RS station is deferred to Sect. 4.

\subsubsection{Global coverage}

The global radiosonde network evolved over time in an uneven manner. Its geographical distribution and temporal evolution are accessed by mapping the IGRA-RS fixed stations

\footnotetext{
${ }^{6}$ GRUAN Lead Centre, Lindenberg Meteorological Observatory - Richard Aßmann Observatory, Germany.
}

at significant times, highlighting the stations that have measured humidity. Latitudinal differences are basically quantified by the annual number of tropical and extratropical stations in each hemisphere. The spatial coverage of observations is further studied by a parameter that is closely related to the average spacing of stations, but it better represents the data coverage if stations are unevenly distributed, as explained below.

The average separation between adjacent stations $(L)$ over a region of the Earth's surface can be estimated by $\sqrt{A / n}$, where $n$ is the number of stations lying on a surface of area $A$, $n / A$ representing the average station density. This measure is, however, insensible to the spatial distribution of stations. The global radiosonde network has highly variable density since the observation stations are concentrated in continental regions, mostly in populated areas of developed countries. Sparse-data areas occur over oceans and seas, near the poles and in certain parts of land continents. $L$ can be alternatively defined as the mean distance between each station and its nearest neighbor; but this definition ignores data-void areas. The average distance from a point on the surface to the nearest station $(\approx L / 2$ for a uniform network) is more informative because it depends on the distribution of concentratedand sparse-data areas. Therefore, to study the global coverage of observations it is convenient to use the average distance to the nearest station, as measured from every point over the main landmasses or ocean/sea areas within a given latitude band. Let $s(x)$ be the geodesic distance from a given point $x=(\varphi \lambda)$ of latitude $\varphi$ and longitude $\lambda$ to the position of the nearest station: $s=\min \left\{\operatorname{dist}\left(x, x_{i}\right) ; i=1,2, \ldots, N\right\}$, where $x_{i}$ denotes the positions of individual stations, say $N$ in total. Averaging $s$ over a zonal band bounded by latitudes $\varphi_{1}$ and $\varphi_{2}$, under the spherical-Earth approximation,

$\bar{s}\left(\varphi_{1}, \varphi_{2}\right)=\int_{0}^{2 \pi} \int_{\varphi_{1}}^{\varphi_{2}} \sigma s \cos \varphi \mathrm{d} \varphi \mathrm{d} \lambda / \int_{0}^{2 \pi} \int_{\varphi_{1}}^{\varphi_{2}} \sigma \cos \varphi \mathrm{d} \varphi \mathrm{d} \lambda$,

where the overbar denotes area-weighted average, and $\sigma(\varphi, \lambda)$ is a mask value that can be used to restrict the calculation to mostly land or water regions by switching the values $\sigma=0$ and $\sigma=1$ appropriately. The following method was applied. First, the calculation for main landmasses excludes points on landmasses smaller than Ireland since they give irrelevant information about the spacing of stations over land; however, continental archipelagos are treated as part of continents. Secondly, any regions outside the above-defined main landmasses are treated as belonging to ocean/sea, excluding lakes which are included in continents. Finally, the determination of the nearest station from points in ocean/sea areas involves not only stations surrounded by sea water (stations on oceanic islands plus a few fixed weather ships, since we focus on fixed stations) but also stations located on the coastline of continents and large islands, as well as on the shores of seas enclosed by continents. This scheme assumes 
that upper-air observations at such locations are partly representative of atmospheric conditions above the nearby waters because the physical frontier between land and sea is blurred in the atmosphere (incidentally, the island and coastal surface stations are classified by the WMO as "sea stations"). The surface integrals were calculated using a $0.5^{\circ} \times 0.5^{\circ}$ latitudelongitude mesh.

We have applied Eq. (1) to the IGRA-RS fixed stations reporting humidity in certain years to examine the global coverage of upper-air humidity observations in different latitude zones over time, regardless of the temporal and vertical completeness of time series. Such information is not part of the dataset introduced in this paper, which focuses precisely on the time series at each station. Nevertheless, Eq. (1), with possible adaptions for the latitude and longitude intervals, may be used to study the spatial coverage of any subset of stations selected according to a given range for the metadata parameters presented in Sect. 4 .

\subsubsection{Annual frequency and temporal continuity}

The frequency of humidity observations over time is studied in terms of the fraction of humidity observing days in the year. Although this gives a sense of the regularity of observations, it says little about the continuity of data over the year. In this respect, it is of interest to know the size of the maximum interval of consecutive days without humidity data in a year - denoted hereafter as "size of missing days".

The above-defined measures of temporal completeness are critical to study climatic trends (long-term changes in the annual mean or in the seasonal cycle of humidity-related quantities) on specific locations or areas of the globe, which otherwise requires merging procedures using radiosonde data from nearby locations to circumvent large data gaps. We have averaged both quantities across all fixed stations reporting humidity within each major latitude region, year by year.

\subsubsection{Vertical resolution and vertical extent}

Since the vertical resolution varies with height - according to the height of the reported pressure levels (standard and significant) and depending on the number of levels with nonmissing data for humidity - the vertical resolution of an individual sounding must be defined by a vertical average. Since the vertical distance between consecutive levels, say $\mathrm{d} z_{k}$, generally increases with height, with the lower levels being more populated than the upper layers, a geometric mean is more suitable than an arithmetic mean. So, the mean vertical resolution of a single humidity sounding is here defined by the geometric mean of $\left\{\mathrm{d} z_{k}\right\}$ for all levels with humidity data in the sounding profile:

mean vertical resolution $=\frac{R_{\mathrm{d}}}{g_{0}} \prod_{k=1}^{M}\left(\bar{T}_{k} \ln \frac{p_{k-1}}{p_{k}}\right)^{1 / M}$, where $p_{k}$ is the atmospheric pressure at level $k(k=0$ denoting the lowest level with humidity data), $M$ is the number of levels with humidity data above the lowest level, $\bar{T}_{k}$ is the estimated mean temperature between level $k$ and its immediate relevant lower level $k-1, R_{\mathrm{d}}$ is the specific gas constant for dry air, and $g_{0}$ is the standard gravity. (Note that IGRA's data-quality checks assure that vertical levels with valid humidity data also have valid temperature and pressure data.)

Since geopotential altitude is only given in part of the RAOB reports, the vertical extent of an individual humidity sounding, i.e., the maximum height above mean sea level reached by the humidity measurements, is consistently estimated by adding the station's elevation to the height from the surface calculated upon pressure and temperature data from the surface level up to the top of the humidity sounding (highest level with a non-missing value for DPD or RH), whenever values of temperature and pressure at the surface are given; otherwise the height from the surface cannot be calculated. For mobile stations (ships and buoys), the elevation of the stations can be approximated to zero, unless the vertical extent of the sounding is too small, requiring, in that event, data for the balloon release height. For the present purpose, it suffices to neglect moisture in the hypsometric equation; given that the virtual temperature is typically within $4 \mathrm{~K}$ above the actual temperature, the error in calculating geopotential height amounts to less than $1 \%$.

Following the above definitions, we have studied the statistical distributions of the vertical extent and the vertical resolution in humidity soundings from IGRA-RS stations (including mobile) over time by grouping individual values of both parameters in annual bins. To assess the shortness of humidity observations in RAOBs, we have also calculated the vertical extent of temperature observations and their vertical resolution up to the top of the co-located humidity observations.

\subsubsection{Soundings eligible to estimate precipitable water vapor}

Usually, the precipitable water vapor (column-integrated water vapor mass per unit surface area) is estimated from the profile of water vapor mixing ratio between the surface and the $500 \mathrm{hPa}$ level - i.e., the layer where $\sim 95 \%$ of the columnar mass of water vapor is and where humidity data from radiosondes are more often available and generally more accurate (Elliot et al., 1991; Gaffen et al., 1992; Ross and Elliott, 1996; Durre et al., 2009). In this paper, a humidity profile is considered eligible to estimate precipitable water vapor under the following conditions:

i. Humidity data are given at the station's surface and at all standard levels laying between the surface and the $500 \mathrm{hPa}$ level, except for the $925 \mathrm{hPa}$ level.

ii. If humidity data are missing at a standard level apart from $925 \mathrm{hPa}$, a nearby significant level is acceptable if 
its height from the surface differs from the height of the missing standard level by less than $5 \%$.

iii. The distance between any consecutive levels with humidity data between the surface and the lowest level located more than $1 \mathrm{~km}$ away from the surface should not exceed $1 \mathrm{~km}$, unless the station elevation is larger than $500 \mathrm{~m}$.

The $925 \mathrm{hPa}$ level is not required here because this level was not standard until 1991. However, condition (iii) assures a minimal resolution in the planetary boundary layer, by including near-surface significant levels as well as the $925 \mathrm{hPa}$ level when it is given; this is required because water vapor is highly variable and abundant in this region; the exception for very elevated stations contemplates the case when the first upper-air humidity record is at $850 \mathrm{hPa}$, i.e., $\approx 1.5 \mathrm{~km}$ above the mean sea level, but the height from the surface is less than $1 \mathrm{~km}$. The IGRA-RS soundings fulfilling the above conditions will be hereafter referred to as $S f$-to-500hPa humidity soundings.

Typically, the first standard level higher than $1 \mathrm{~km}$ from the ground is $850 \mathrm{hPa}$. Thus, by including enough data at significant levels below the $850 \mathrm{hPa}$ level, instead of requiring data at the current standard levels in the same layer - sorted out of 925 and $1000 \mathrm{hPa}$, depending on the surface pressure the definition given above accommodates much more soundings, particularly before 1992 when the $925 \mathrm{hPa}$ level was not mandatory. To be sure, the relative number of humidity observations at near-surface levels is now examined, excluding $1000 \mathrm{hPa}$ (around $0.1 \mathrm{~km}$ in altitude) since this is frequently placed below the stations' elevation (339 $\mathrm{m}$ on average for the IGRA-RS fixed stations).

Figure 2 shows the evolution of the global percentage of humidity observations at the $925 \mathrm{hPa}$ level and at any significant level between the surface and $850 \mathrm{hPa}$, out of the IGRA-RS soundings having humidity data at the surface on the condition that the surface level pressure is higher than 925 and $850 \mathrm{hPa}$, respectively (referred to in the following as surface-upper-air soundings). The percentage of surface observations in all humidity soundings is also shown. First, note that the surface observations began in 1943 (in fact, not only of humidity but also of temperature), rising rapidly in the next 5 years to $\approx 95 \%$ of the humidity soundings, decreasing then to a minimum of $60 \%$ in 1965 and broadly increasing again until 2000, staying above $95 \%$ since then. In short, the humidity measurements at the surface level are mostly available since 1945 but have been in widespread use only since 2000. Secondly, the percentage of the surface-upperair soundings having humidity data at the $925 \mathrm{~Pa}$ increased almost as a step function around 1992. It increased from only $2 \%$ in 1991 to $60 \%, 86 \%$, and $98 \%$ in the following three years. This change is coincident with the introduction of the $925 \mathrm{hPa}$ level as an additional standard level in radiosonde messages in November 1991, and consistent with the fraction of stations already reporting that level in mid-1993 (Oakley,

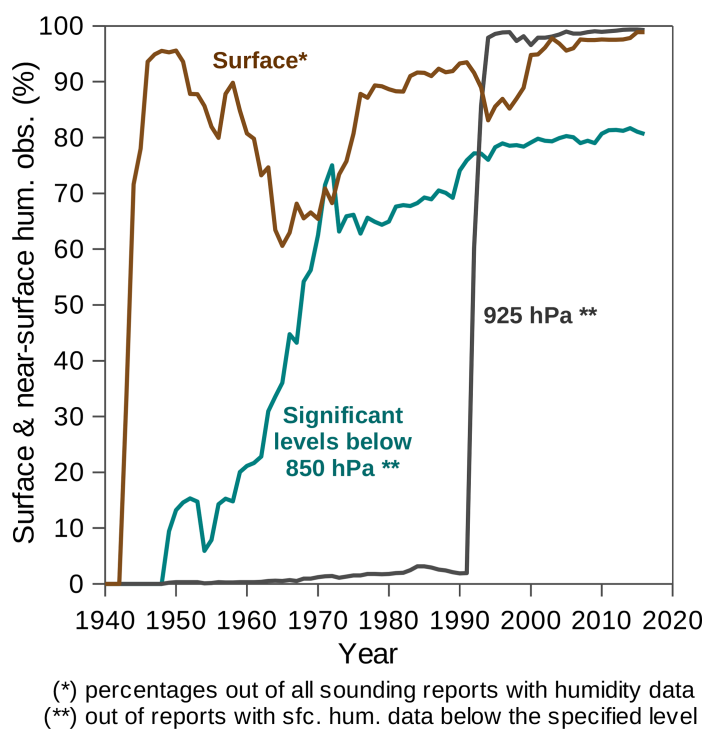

Figure 2. Percentage of humidity observations: at the surface level out of all humidity soundings in each year; at $925 \mathrm{hPa}$, out of the soundings with surface data below that level; and at any nonstandard level - excluding $925 \mathrm{hPa}$, irrespective of the year - between the surface and the $850 \mathrm{hPa}$ level, whenever this is above the surface.

1993, p. 24). Lastly, the percentage of the surface-upper-air soundings that have humidity data at any significant level below the $850 \mathrm{hPa}$ level, beginning in 1948, generally increased with time, mainly in the 1960 s, with a value larger than $80 \%$ in recent years.

Using the definition given at the beginning of this section, we have studied the number and the percentage of stations (fixed and mobile) whose Sfc-to-500hPa humidity soundings exceed a given percentage out of the humidity soundings made in each year. The distance between missing standard levels and nearby significant levels was calculated from pressure and temperature data, neglecting moisture. A stricter definition of Sfc-to-500hPa humidity soundings, specifically, having humidity data at the surface and all current upper-air standard levels up to $500 \mathrm{hPa}$, was also studied for comparison.

\subsubsection{Current record length of time series}

The "current record length" of a humidity time series in a given station and year is herein defined as the number of elapsed years in the time series with no gap years in the interim. To simplify, a calendar year with any number of humidity data is counted as one. For past years, the current record length generally differs from the span of the entire time series, which may continue after the year under consideration. Also, note that one station can have more than one time series for humidity, as the humidity observations can be interrupted by one or more gap years. So, the full period of record of a radiosonde station may be divided into several 
sub-periods of record for humidity. Recall that the years with humidity observations at each IGRA-RS station are indicated in Table S1.

We have studied the evolution of the average current record length of the humidity time series, from all stations, year by year. The same was done for the time series with humidity soundings $90 \%$ of the days in the year, at least, and particularly consisting of Sfc-to-500hPa soundings, with their own record lengths. The calculation of the distribution of the current record length of the time series with Sfcto- $500 \mathrm{hPa}$ soundings $90 \%$ of the days in the year or more was repeated by restricting the corresponding size of missing days to less than $10 \mathrm{~d}$.

\section{Overview on the completeness of radiosonde humidity observations}

This section gives a general picture of the completeness of humidity observations over the years, using the data from the IGRA-RS stations defined in Sect. 2.2 and following the data analysis described in Sect. 2.3. The results of Sect. 3.1 and 3.2 refer to fixed stations, i.e., over 1600 stations on continents and islands, 14 fixed ocean weather ships, and two environmental buoys. In the remaining Sect. 3.3-3.5 mobile stations (99 ships) are equally included (see Table S1; moving stations are denoted by unspecified geographical coordinates).

\subsection{Geographical coverage of humidity observations}

Figure 3 shows the geographical distribution of the IGRARS fixed stations at specific years illustrating the nonlinear growth of the global radiosonde network (see Fig. 1a); stations reporting humidity observations are highlighted and counted. Recall that a single station can change from PIBAL observations to RAOBs, or even the reverse, during its period of activity. The IGRA-RS retains practically all RAOB data of IGRA; however, some stations have years with only PIBAL observations. Since almost all of the IGRA stations measuring temperature in a given year since 1945 do also measure humidity at least part of the time (as seen by comparing black and solid blue lines in Fig. 1a), it is clear that most of the IGRA-RS station years without humidity data (red crosses in Fig. 3) correspond to years of PIBAL observations alone (no RAOBs). Concerning humidity observations, Fig. 3 shows that by 1945 there were only 29 observation sites (with enough data to be archived in IGRA) and that two-thirds of them were set in South Asia (previously British India) and Australia. Most of the data coverage over North America, Greenland, Europe, and north Asia, including the Arctic region, as well as over the surrounding oceans, took place between 1945 and 1955. By 1975, central and Southeast Asia, Africa, South America, Antarctica (along its coastline, except for the Amundsen-Scott South Pole Station), and the surrounding oceans were already covered - al- though not as well as farther north regarding the continental regions, with the noteworthy exception of China. While the global number of fixed stations measuring humidity (about 820 ) has remained practically unchanged since then (see also Fig. 4), their geographical distribution changed significantly. At present (2015) there are more observation sites in South America, much fewer in central and east Africa, much more in western Asia, and a more evenly distributed network in the rest of the world.

Although oceans have been mainly covered by island stations, ocean weather ships (stationed) were important for almost 30 years, between the mid-1940s and the early 1970s. Judging from IGRA data, coverage from these ships was optimal between 1967 and 1972, with 7 to 12 units transmitting radiosonde observations simultaneously, although almost all were located in the North Atlantic except for one ship in the Norwegian Sea and another one in the North Pacific. Apparently, upper-air observations from these platforms ended a few years later (save for the station " $\mathrm{M}$ " in the Norwegian Sea, which continued until 1990), coincident with the growing use of satellite retrievals in weather forecasting. However, in situ data coverage on oceans was improved by using balloon sounding systems on board merchant ships - which obviously are not shown in Fig. 3. About 10 to 20 ships of opportunity have launched radiosondes concurrently along their routes from the 1980s to present. Other floating, mobile stations are also worth mention. The automated ice-drifting stations surveying the north polar region during 1950-1991 were important considering their location and the number of data gathered over the years. The missions to the Arctic and Antarctica performed by the icebreaker and research vessel Polarstern (Driemel et al., 2016), also covering Atlantic Ocean regions during transit, provided substantial radiosonde humidity data in the periods 1985-1993 and 20002014. The weather ship Polarfront accounts for the largest number of moving radiosonde data (after manning station " $M$ " in the 1980's) but it operated only in the Norwegian Sea. For statistics about the humidity observations from all floating stations included in IGRA (fixed and mobile), see the end of Table S1.

Figure 4 shows the count of fixed IGRA-RS stations with humidity observations in each year since 1930, by latitude bands of equal area, representing approximately tropical (0$30^{\circ}$ ) and extratropical $\left(30-90^{\circ}\right)$ latitudes in each hemisphere. One can see that before 1937 there was only one observing station and three years without data (1933-1934 and 1936). The few humidity-reporting stations existing by 1940 were placed in the Northern Hemisphere (in fact, most of them were in the Arctic). From 1945 on, they were located predominantly in the northern extratropics, even though their number had grown in other latitudes, at the fastest rate in the subsequent 2 decades. From 1970 onwards, the number of stations in the southern extratropics did not follow the growth observed elsewhere. This is not surprising since regions south of parallel $30^{\circ} \mathrm{S}$ have significantly more ocean 

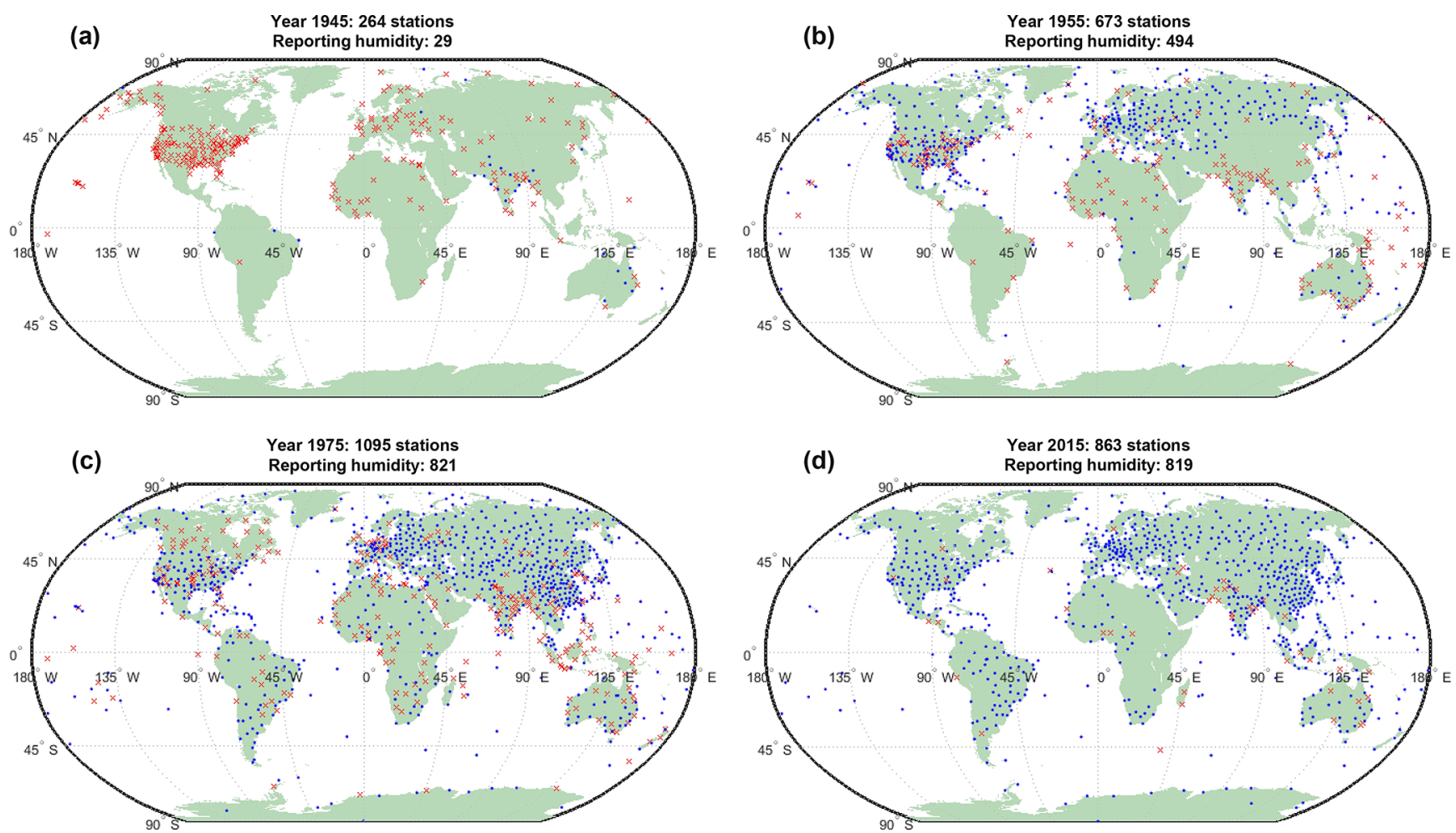

Figure 3. Locations of IGRA-RS fixed stations active in the years of (a) 1945, (b) 1955, (c) 1975, and (d) 2015. Note the interval of time doubles between consecutive panels. Blue dots denote the stations reporting humidity (RH/DPD + temperature) anytime in the year; red crosses denote stations reporting only temperature/wind, or else presenting a data record gap, during the same year. The total number of stations (crosses + dots) refers to the active stations in each year regardless of any data record gaps.

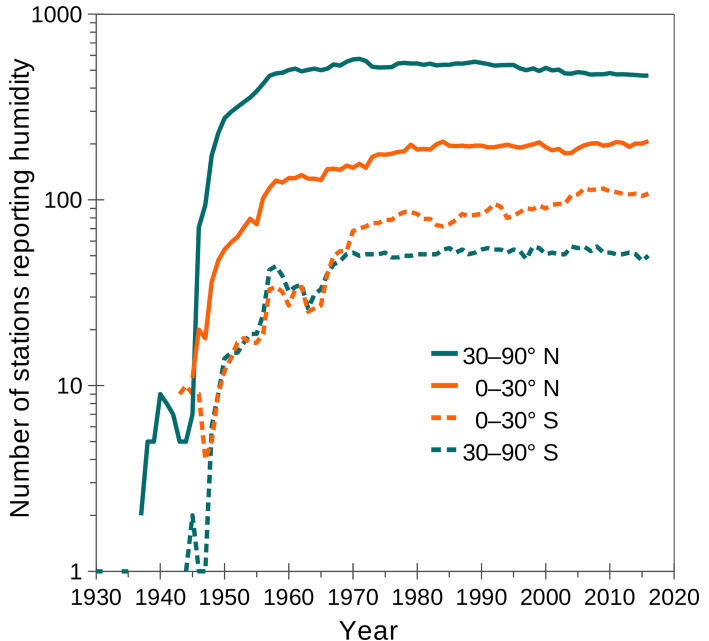

Figure 4. Yearly number of IGRA-RS fixed stations reporting humidity in northern and southern tropical and extratropical latitudes, since the time of the earliest radiosonde humidity observations.

and less land. Note that the absence of mobile stations affects Fig. 4 very little, since mobile stations are short numbered and have a short period of record (a few years), despite being important in covering the oceans. The northern extrat- ropics have accounted for about half of the world stations for decades, although their relative weight has been decreasing over the years; the decrease in number of stations situated in that region after 1990 is counterbalanced by an increase in the tropics since then.

Using Eq. (1) and the method outlined in Sect. 2.3.1, Fig. 5a-b show the average distance to the nearest station $(\bar{s})$ as calculated from points on mostly land or in ocean/sea regions within several latitude bands for every 15 years beginning in 1955, when the global radiosonde network was barely established. Figure 5c shows a similar calculation but for the total surface area of each latitude band. Clearly, since at least 1970, $\bar{s}$ has changed little over continents and large islands at all latitudes, with values ranging from $\sim 200 \mathrm{~km}$ in land areas of the northern temperate latitudes $\left(35.0-66.5^{\circ} \mathrm{N}\right)$ to $\sim 700 \mathrm{~km}$ in land areas of the southern polar region $(66.5$ $\left.90.0^{\circ} \mathrm{S}\right)$, i.e., in Antarctica. In the tropics $\left(23.5^{\circ} \mathrm{S}-23.5^{\circ} \mathrm{N}\right)$, where $\bar{s} \sim 500 \mathrm{~km}$ over land during the same period, the little change observed despite considerable changes in the distribution of continental stations can be explained as follows: the better spatial coverage over South America at present is offset by the poorer coverage over a large part of sub-Saharan Africa, save for the country of South Africa (see Fig. 3c and d). In contrast, in ocean/sea regions $\bar{s}$ not only is 2 to 3 times 

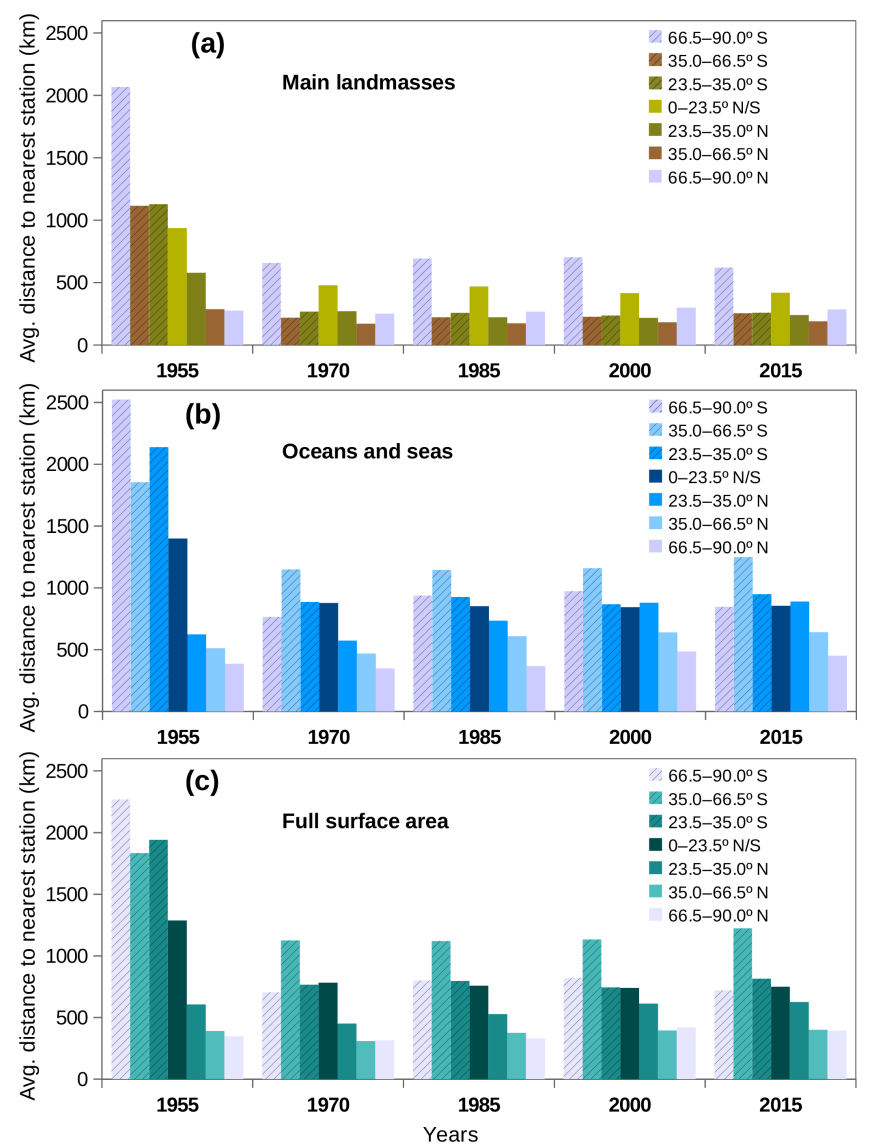

Figure 5. Average distance to the nearest station, among the humidity-reporting stations from 1955 to 2015 in 15-year intervals, as calculated in specific areas of each latitude zone (see insets): (a) main landmasses; (b) oceans and seas; (c) full surface area. See text for calculation details (Sect. 2.3.1).

larger than over land regions - except in the southern polar region, i.e., in the Southern Ocean when compared to Antarctica - but has also degraded slightly over time in the Northern Hemisphere oceans and seas from the subtropics (23.5$\left.35^{\circ} \mathrm{N}\right)$ to the $\operatorname{Arctic}\left(66.5-90^{\circ} \mathrm{N}\right)$. From a global perspective, the hemispheric differences in $\bar{s}$ due to the distribution of oceans and continents can be appreciated in Fig. 5c. Note that $2 \bar{s}$ gives an estimate of the average separation between adjacent stations in regions where the radiosonde network is relatively regular. For example, Fig. 5a indicates a typical separation of about $400 \mathrm{~km}$ in the northern temperate continental regions (coincident with the wealthier countries of the North Hemisphere) - which is acceptable for synoptic weather forecasting. While the same is impracticable in many other parts of the world and over the oceans, distances up to 2 or 3 times larger than ideal need to be filled by satellite-based data and supplemented by surface observations, which are generally much denser than radiosonde stations. Nevertheless, on a scale suitable for climate monitoring, the WMO recommends that upper-air stations should have a maximum average sep-

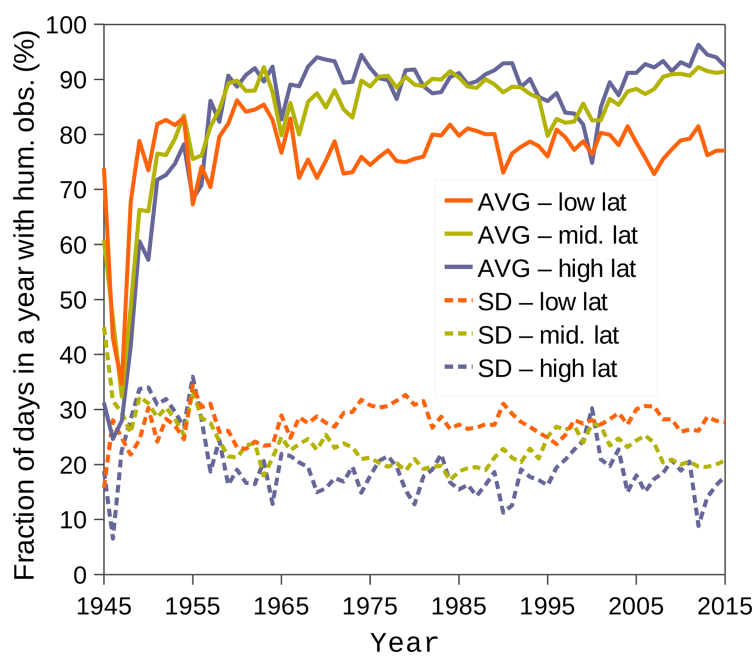

Figure 6. Statistical measures of the fraction of days in a year with humidity observations from 1945 to 2015 , representing the fixed radiosonde stations over the major latitude regions for both hemispheres: average among stations with humidity data, and standard deviation. Low lat - abs. latitudes $<30^{\circ}$; mid. lat - abs. latitudes between 30 and $60^{\circ}$; high lat - abs. latitudes $>60^{\circ}$.

aration of $1000 \mathrm{~km}$ (WMO, 2011b). This would require $\bar{s} \leq$ $500 \mathrm{~km}$. Figure $5 \mathrm{~b}-$ which by including coastal stations does not represent the actual station density in deep-ocean areas indicates that fixed stations are too far apart in most oceans, particularly in the southern midlatitudes where $\bar{s}>1000 \mathrm{~km}$.

\subsection{Average fraction of days in a year with humidity observations and size of missing days}

Figure 6 represents the fraction of days in a year having humidity observations, averaged across all humidity-reporting fixed stations in each of the three major latitude regions of both hemispheres, along with the standard deviation. The plot begins in 1945, about when humidity measurements by radiosondes became routine (see Fig. 1). In all regions, the average fraction of the days in a year with humidity observations increased rapidly until around 1960, stabilizing since 1965 to values in the range of $70 \%-80 \%$ in low latitudes and $80 \%-95 \%$ in midlatitudes and high latitudes. The corresponding standard deviations indicate that a non-negligible percentage of the stations have observations on every day in the year since the 1950s.

Figure 7 represents the typical size of missing days in humidity observations in each year, as averaged across the fixed stations located within each major latitude zone. Recall that we focus only on sub-year missing days since gaps of one or more years are exceptions related to interruptions of a station's operation or maybe to the lack of a functioning hygrometer. Thus, Fig. 7 summarizes the typical continuity of humidity time series having any observations in the year. As a general picture, the average size of missing days 


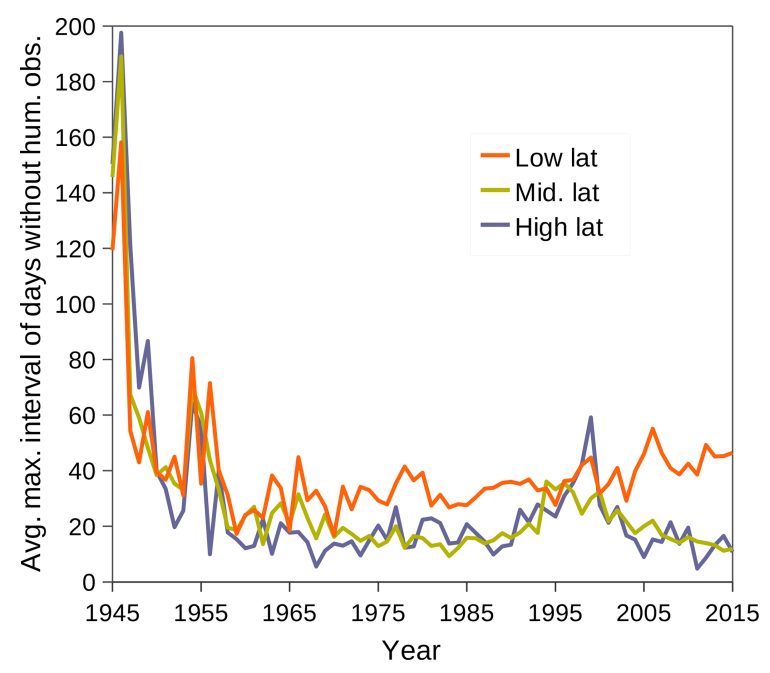

Figure 7. Maximum number of consecutive days without humidity data in each year with some humidity observations ("size of missing days"), averaged among the fixed stations within each of the major latitude regions defined as in Fig. 6.

dropped from 4-6 months to about 1 month between 1945 and 1960; much of this change occurred before 1950, indicating that radiosonde measurements became rapidly regular in the early years. From 1960 to 2015, the stations at low latitudes present a trend in the size of missing days, from $\approx 30$ to $40 \mathrm{~d}$ on average; while stations at midlatitudes to high latitudes present typical values of $\approx 20 \mathrm{~d}$, except during the mid-1990s $(\approx 30 \mathrm{~d})$. Nonetheless, the dispersion of values away from the mean (not shown) indicates that some stations have time series much more continuous than others, e.g., with daily data throughout the whole year.

The fraction of days with humidity observations, the size of missing days, and the count of observations, detailed by station and year, are part of the first metadataset presented in this paper (see Sect. 4.1). Note that gap years are also evaluated in the metadata. Similar information is given for the Sfc-to-500hPa humidity soundings alone.

\subsection{Global vertical extent and resolution of humidity observations}

Figure $8 \mathrm{a}$ shows the distribution of the vertical-mean resolution in the annual humidity soundings since 1945, along with the homologous distribution in the simultaneous temperature soundings, limited to the highest level with humidity measurements for comparison. The vertical-mean resolution of each sounding was calculated by Eq. (2), rounded to the nearest decameter. For clarity, the curves displaying the mean and the quartiles are smoothed by a 5-year running mean. The differences between the distributions for temperature and humidity indicate missing humidity data in a few percent of the vertical levels with temperature data; although statistically irrelevant, such vertical gaps may be quite significant in indi- vidual soundings. The vertical resolution was relatively poor on average and highly variable in the early decades: until around 1965 the mean and median were coincident and varied in the range of $1.1-1.4 \mathrm{~km}$, with a midspread (interquartile range) of almost $1 \mathrm{~km}$. Both the average resolution and the midspread improved consistently from 1965 to between 2000 and 2005 . Since $2005,75 \%$ of the soundings have a vertical-mean resolution better than $0.5 \mathrm{~km}$, with half of the values ranging from 0.3 to $0.5 \mathrm{~km}$.

Figure $8 \mathrm{~b}$ shows how the maximum height above the mean sea level reached by either temperature or humidity measurements is distributed among the corresponding soundings for each year. Curves are smoothed by a 5-year running mean, as in Fig. 8a. But the distribution is restricted to temperature and humidity soundings with surface data, these representing, respectively, $86.7 \%$ and $86.0 \%$ of the total RAOB soundings in the period 1945-2016. In addition, the soundings from mobile stations with missing geopotential height at the surface level are excluded, for consistency with the hypsometric calculations used in the dataset presented in this paper. According to Fig. 8b, by $2003,75 \%$ of the temperature soundings with surface data reached an altitude of $22 \mathrm{~km}$, i.e., $\sim 50 \mathrm{hPa}$. Note that Durre et al. (2006) reported that, by the same year, $74 \%$ of all IGRA 1 soundings reached at least the $100 \mathrm{hPa}$ level, i.e., $\sim 16 \mathrm{~km}$; this lower height is due to the inclusion of PIBAL data in their analysis of IGRA 1, whereas our analysis is restricted to RAOBs in IGRA 2.

Contrary to temperature, which can be measured up to the maximum height achieved by the sounding balloon (burst altitude, although the highest reported level is usually limited by the standard levels in use), the vertical reach of humidity measurements depends on the working range of humidity sensors and, to some degree, on reporting practices. In Fig. $8 \mathrm{~b}$ we can observe that the top of the humidity observations is at present situated almost $5 \mathrm{~km}$ below the maximum altitude of the temperature measurements (close to the burst altitude) on global average (either mean or median). But the difference in vertical extent between temperature and humidity observations has changed greatly over the years, with a maximum mean value of $12.5 \mathrm{~km}$ by 1980 . Until the late 1960s the top of temperature observations increased at a much faster rate than the top of humidity observations, except for a few years after 1965 when the reverse happened. This last feature is coincident with the introduction of the carbon hygristor. Likewise, the isolated peak of the global mean maximum height of humidity observations around 1970, as seen in Fig. 8b ("HUM"), seems to indicate an exploratory period with the new instrument. Noteworthy, in 1970 the WMO stated that "no routine observations of humidity are made in the stratosphere and no practical use is envisaged for such current observations" (Hawson, 1970). Figure $8 b$ undoubtedly shows that humidity was mostly measured in the troposphere until the mid-1960s. In contrast, from the mid-1980s onwards, the vertical extent of humidity observations has increased consistently and faster 

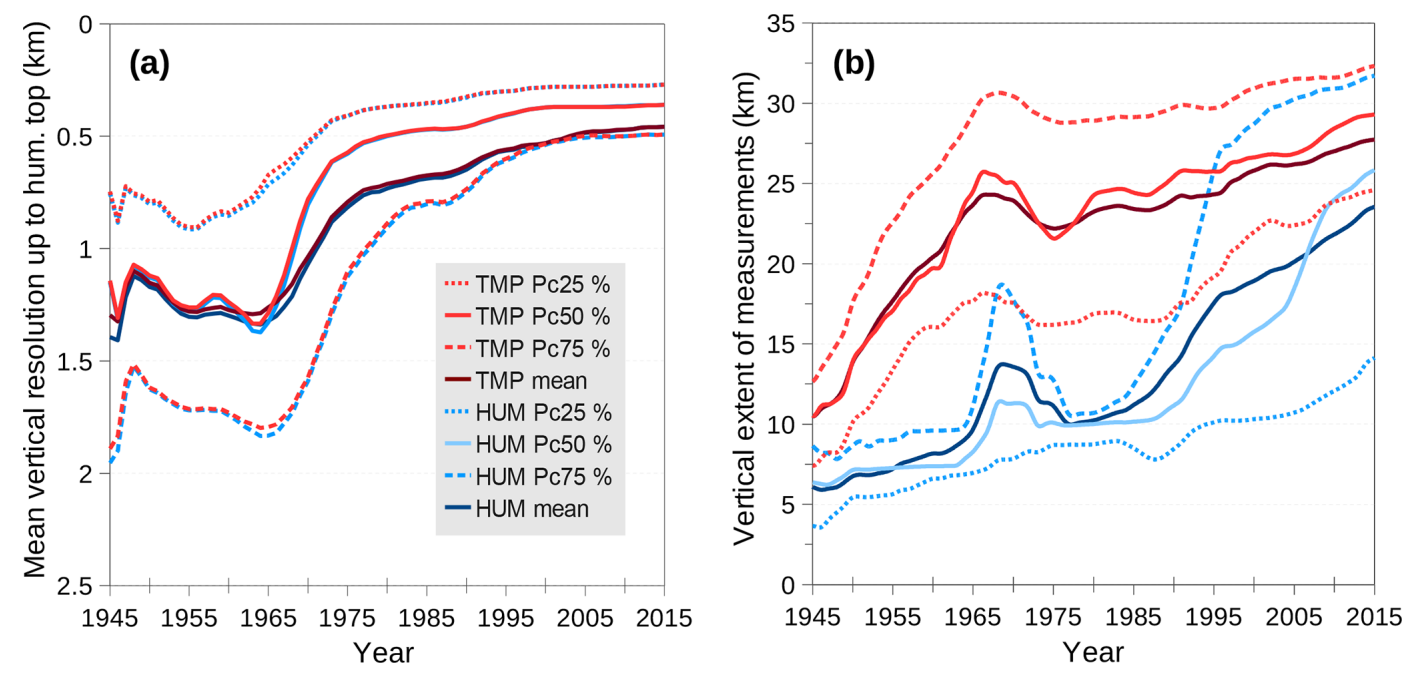

Figure 8. (a) Distribution of the "mean vertical resolution" (definition of Eq. 2) in the temperature (TMP) and humidity (HUM) observations across the globe, calculated up to the highest measuring level for humidity: mean and quartiles. (b) As in panel (a), but for the vertical extent of TMP and HUM observations, restricted to observations with surface temperature data. All the curves are smoothed by a 5-year running mean.

than the RAOB-top - by roughly $4 \mathrm{~km}$ per decade on global average - denoting improvements of humidity sensors (see Sect. 1.3). In 2015, three-quarters of the humidity-top values extend to over $13 \mathrm{~km}$, and half to over $26 \mathrm{~km}$, indicating that many humidity reports extend into the lower stratosphere. The accuracy of radiosonde humidity measurements in the stratosphere is beyond the scope of this paper. However, only 15 years ago, international experts pointed out that the accuracy of current operational measurements of humidity in the upper-troposphere was inadequate for addressing climate variability and change (despite the usefulness of some sensors) and a challenge for future operational radiosondes (Durre et al., 2005). It is interesting to note that the interquartile range of the top height of humidity soundings has increased much in the period 1985-2000, i.e., individual values became widely dispersed around the median. This is likely related to the proliferation of humidity sensors of different kinds, thus increasing the instrument variations among stations as new instruments coexist with older ones. For instance, by 1989 the WMO had identified 20 major radiosonde types in use worldwide (Kitchen, 1989a). While this number has fallen to 13 by 2002 (Elms, 2003), Fig. 8b shows that the dispersion in the vertical range of different humidity sensors has increased in the meantime; changes in instrument-dependent observing practices may have a role.

The average vertical resolution of the humidity observations, by year and station, as well as the individual values by station, date, and time, are given in the metadatasets provided in this paper (see Sect. 4). Similar metadata are provided for the Sfc-to-500hPa humidity soundings, as defined in Sect. 2.3.4, in which case the vertical resolution is calcu- lated for the levels between the surface and the $500 \mathrm{hPa}$ level and is normally finer than depicted in Fig. 8a.

Since IGRA-RS observations do not have surface humidity data prior to 1945 , and surface data are not always given after that year, to account for all soundings the vertical extent of humidity observations must be alternatively represented by the lowest pressure corresponding to humidity data. The same applies to soundings from mobile stations if geopotential height is not given at the surface level (it is missing in $30 \%$ of the corresponding RAOBs). Although the local sea level is normally within $\pm 10 \mathrm{~m}$ from mean sea level, taking zero as the baseline height can lead to large relative errors if humidity is only measured very close to the radiosonde station elevation (balloon release height). Therefore, the annual average pressure of the top of humidity soundings, by station and year, is given in the first metadataset presented in this paper; average values are represented by a geometric mean (see Sect. 4.1). As for the second set for individual observations - metadata by station, date, and time - both the top pressure and the corresponding altitude, whenever altitude can be calculated, are provided (see Sect. 4.2).

\subsection{Number of stations by completeness of Sfc-to-500hPa humidity data}

Recall that our definition of Sfc-to-500hPa humidity soundings (Sect. 2.3.4) is intended to represent the soundings with enough vertical levels, and almost evenly distributed near the surface, such that the water vapor profiles can be properly described and the precipitable water can be estimated. In this respect, the completeness of such humidity observations based on current standard pressure levels alone is unsatisfactory for two reasons: first, the level $925 \mathrm{hPa}$ was barely used 
before 1992 (see Fig. 2); second, the sounding data at significant levels, often related to features of temperature rather than $\mathrm{RH}$, or at other additional levels, are equally good provided that the vertical resolution (habitually increasing towards the surface) is not too different. Next, we will compare the distribution of Sfc-to-500hPa soundings among IGRARS stations in each year using alternative definitions:

A. humidity data at the surface and all current standard levels above the surface up to $500 \mathrm{hPa}$, i.e., at pressure levels $\left\{p: p \in\{1000,925,850,700,500 \mathrm{hPa}\} \cup\left\{p_{\mathrm{SFC}}\right\}\right.$, $\left.p \leq p_{\mathrm{SFC}}\right\}$

B. definition given in Sect. 2.3.4.

The soundings meeting either of the above two definitions are coined Hum-A or Hum-B in the following analysis. Note, however, that only definition $B$ was used to prepare the metadatasets described later in this paper.

Let $P$ be the percentage of Sfc-to-500hPa soundings (Hum-A or Hum-B, at our choice), out of all humidity soundings from an arbitrary station in a given year. Figure 9a shows the evolution of the number of stations with $P$ for Hum-A soundings exceeding given values since nearly the time radiosonde humidity data at the surface level are first available. Comparing Fig. 9a with Fig. 1a, we can see that between 1945 and 1991 only a small fraction of the radiosonde stations carried out Hum-A observations in most of the soundings, say, with $P$ within the range $P>95 \%$. Things changed drastically between 1992 and 1994, when the number of stations with a significant percentage of Hum-A soundings, e.g., $20 \%<P<80 \%$, increased by an order of magnitude. This change reflects the change in the observing practice shortly after $925 \mathrm{hPa}$ was internationally adopted as a standard pressure level (see Fig. 2). In recent years there are over 400 stations with $P>95 \%$ and almost 800 with $P>80 \%$. Figure 10a shows how the probability of finding a station in IGRA-RS with a percentage of Hum-A soundings exceeding a given value was reversed over the last 5 decades: by 1965 , only $12 \%$ of the stations had at least $20 \%$ of Hum-A soundings, whereas by $2015 \approx 91 \%$ of the stations had at least $80 \%$ of Hum-A soundings.

Figure $9 \mathrm{~b}$ is the counterpart of Fig. $9 \mathrm{a}$, for the less stringent Hum-B soundings. Recall that $925 \mathrm{hPa}$ is now treated in the same way as any near-surface nonstandard level, and, for the rest, significant levels close to standard levels are allowed. (Note that the filling of missing data according to condition (ii) of Sect. 2.3.4 affected $22 \%$ of the total Hum-B soundings.) One can observe that, before 1992, the number of stations having moderate to high percentages $P$ of Hum-B observations is much larger than the number of stations having the same percentages of Hum-A observations; from 1992 on, that difference is moderate and only significant when $P$ is very high. In addition to the sudden increase in the stations with many Hum-B observations in 1992, there are two other noteworthy change points: a sudden increase around 1970 and another one in 2000. These changes are related to the increase in the global percentage of humidity soundings with surface data happening at about the same time (see Fig. 2). For example, the number of stations providing Hum-B vertical profiles in more than $80 \%$ of the soundings doubled from $\approx 40$ to 80 between 1969 and 1971, doubled from 250 to 500 between 1990 and 1993, and increased from 520 to 700 between 1999 and 2001; a much more constant value of around 800 is observed in the period 2005-2015. The inverse cumulative distribution function in Fig. 10b indicates the probability of finding a station in IGRA-RS with a percentage of Hum-B soundings exceeding a given value in different trienniums. About 50 years ago, the fraction of stations having at least $20 \%$ of Hum-B soundings was as large as $40 \%$, increasing gradually over time to nearly $100 \%$ at present. Furthermore, $97 \%$ of the presently active stations have at least $80 \%$ of Hum-A soundings.

The number of Hum-B Sfc-to-500hPa humidity soundings at each station and year as well as the fraction of days in a year having such soundings are given in the first metadataset presented in this paper (see Sect. 4.1). Information on the size of missing days and the average vertical resolution is also specified. The metadataset regarding individual observations identifies the $\mathrm{Sfc}$-to-500hPa humidity soundings and provides information on their vertical resolution between the surface and $500 \mathrm{hPa}$ (see Sect. 4.2).

\subsection{Number of long-term time series}

Figure 11a illustrates the number of humidity time series, one per station, fixed or mobile, with a current record length (elapsed years until the year in abscissa) exceeding a given number of decades: 1,3 , and 5 . The time series refer to periods of consecutive years with any observations in the year. For comparison, the same is shown for the time series with data $90 \%$ of the days in the year or more. It should be noted that the concurrent series with more than 10 years of back data begin in 1948, even though the first upper-air humidity measurements began in 1930 and by 1949 there were already around 300 stations measuring humidity (see Fig. 1a). The initial slope of the curves in Fig. 11a denotes the rapid growth of the global radiosonde network after the second World War, with many stations measuring humidity regularly. Nevertheless, the curves are not monotonous, due to the closing of stations in the past and to the existence of gap years in many stations. For instance, if we want to collect the largest number of parallel humidity time series extending back in time to over 10 years, Fig. 11a tells us that we should pick IGRA data until 1987-90, corresponding to about 750 radiosonde stations. However, as of 1976, the number of parallel time series with humidity observations $90 \%$ of the time or more and extending back in time to over 30 years has been increasing over the years, representing 200 stations in 2016. If we consider a much shorter duration, e.g., 10 years as a minimum, the time series until the same year become several times more 

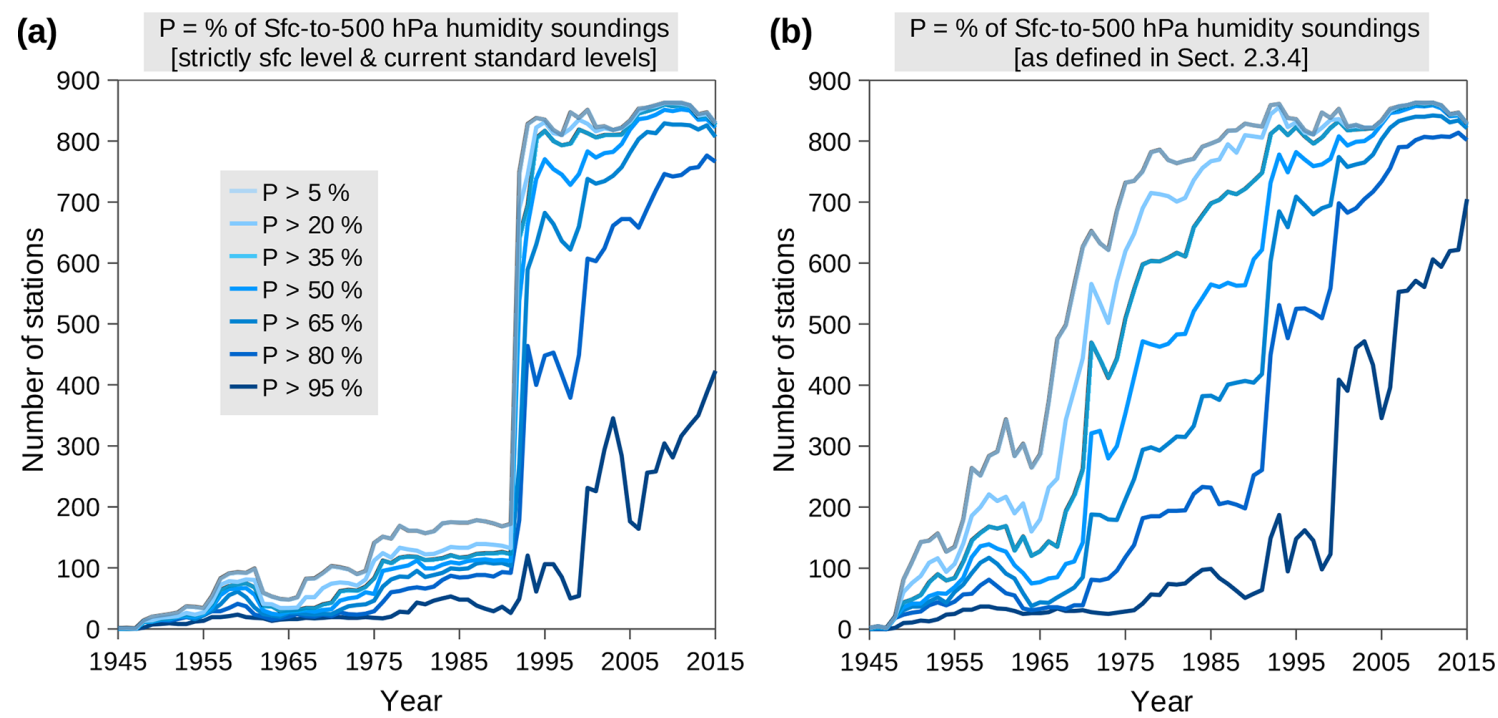

Figure 9. Number of stations for which the percentage of Sfc-to-500hPa humidity soundings, out of all soundings with humidity in each year, exceeds a given value (see inset of panel a): (a) requiring humidity data at the surface level and all current standard levels above the surface up to $500 \mathrm{hPa}$; (b) using the definition of "Sfc-to-500hPa humidity soundings" given in Sect. 2.3.4.

(a) $\mathrm{P}=\%$ Sfc-to-500 hPa hum. obs. (sfc. \& std. levs)

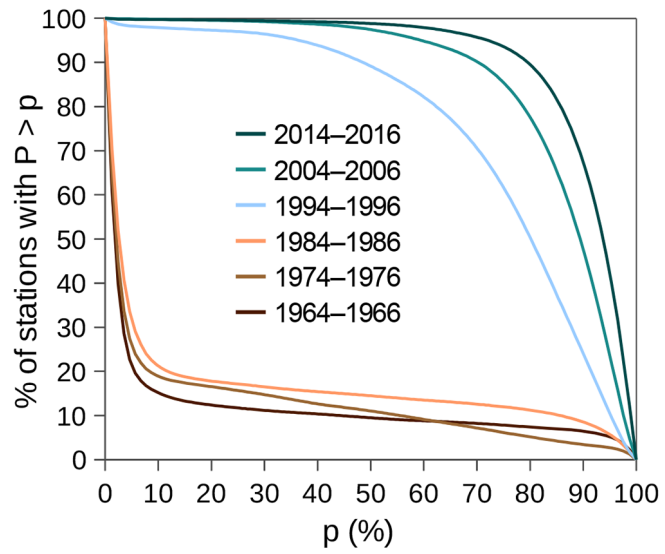

(b) $P=\%$ Sfc-to-500 hPa hum. obs. (def. Sect. 2.3.4)

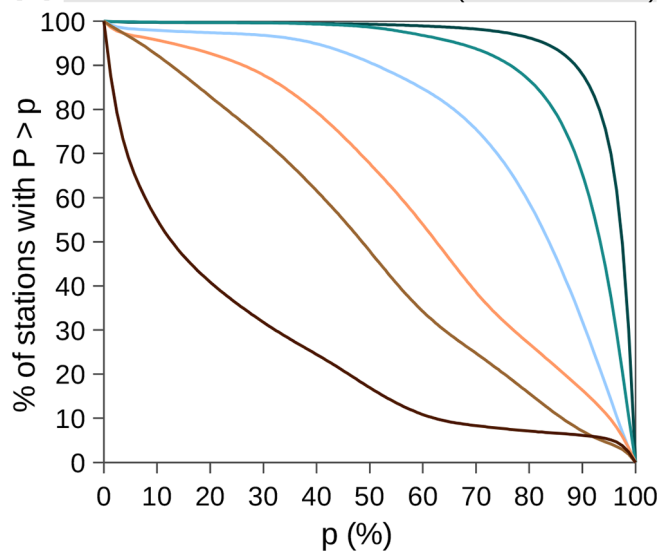

Figure 10. Percentage of stations, out of all IGRA-RS stations, with a percentage of Sfc-to-500hPa humidity soundings exceeding a given value (shown in abscissa), out of the humidity soundings in several trienniums with 10-year intervals (see inset of panel a): (a) requiring humidity data at the surface level and all current standard levels above the surface up to $500 \mathrm{hPa}$; (b) using the definition of "Sfc-to-500hPa humidity soundings" given in Sect. 2.3.4.

numerous and start much earlier. Figure $11 \mathrm{~b}$ represents the distribution of the current record length under more restrictive conditions. First, it considers only the time series consisting of Sfc-to-500hPa soundings (definition of Sect. 2.3.4) covering $90 \%$ of the days in the year or more; secondly, it further limits the time series to those with less than 10 consecutive missing days in every year, meaning that all months are evenly represented. We can see that the number of parallel time series with regular (fraction of days in a year $\geq 90 \%$ ) Sfc-to-500hPa soundings and extending back in time to more than 10 (30) years has increased rapidly since 2000, after 4 (2) decades with a value of less than 100 (20), only then in- creasing steadily to about 330 (50) by 2016 . However, the Sfc-to-500hPa time series with the same length but being almost continuous (fraction of days in a year $\geq 90 \%$; size of missing days $<10 \mathrm{~d}$ ) are much less numerous.

Figure 11 is only illustrative. There is no simple answer to the question of when we have enough data to (in theory) perform climate studies from radiosonde humidity data: it depends on the strictness of completeness criteria. (In practice, it also depends on the accuracy and homogeneity of measurements by different instruments.) Note that the length of the time series under user-specified conditions for any of the metadata parameters defined in the next section, either back- 
(a) Time series with any humidity data in the year (no gap years)

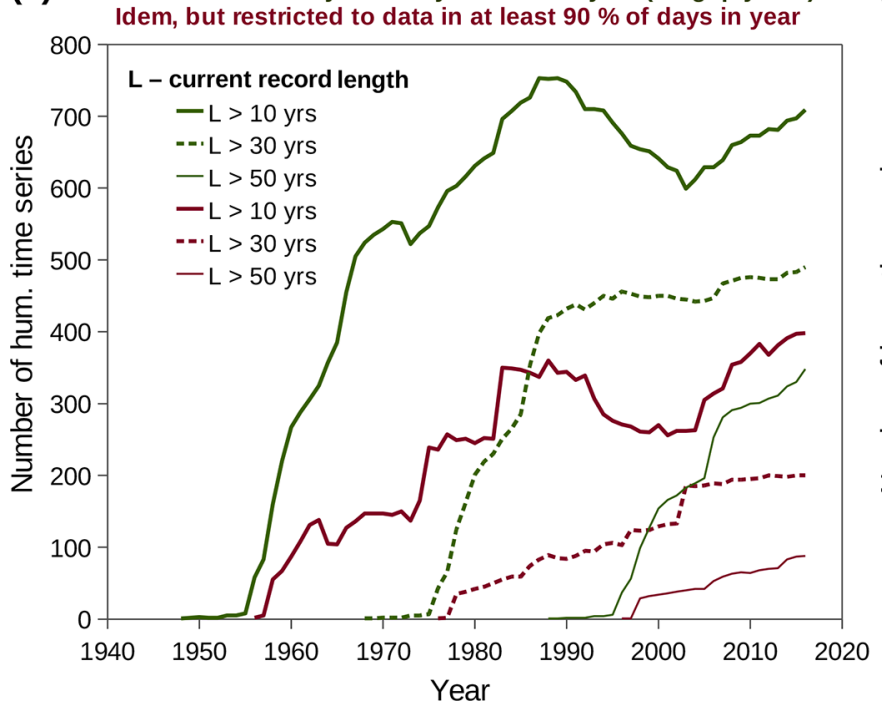

(b) Time series of Sfc-to-500 Pa obs. in at least $90 \%$ of the days in year Idem, but with size of missing days $<10$ days

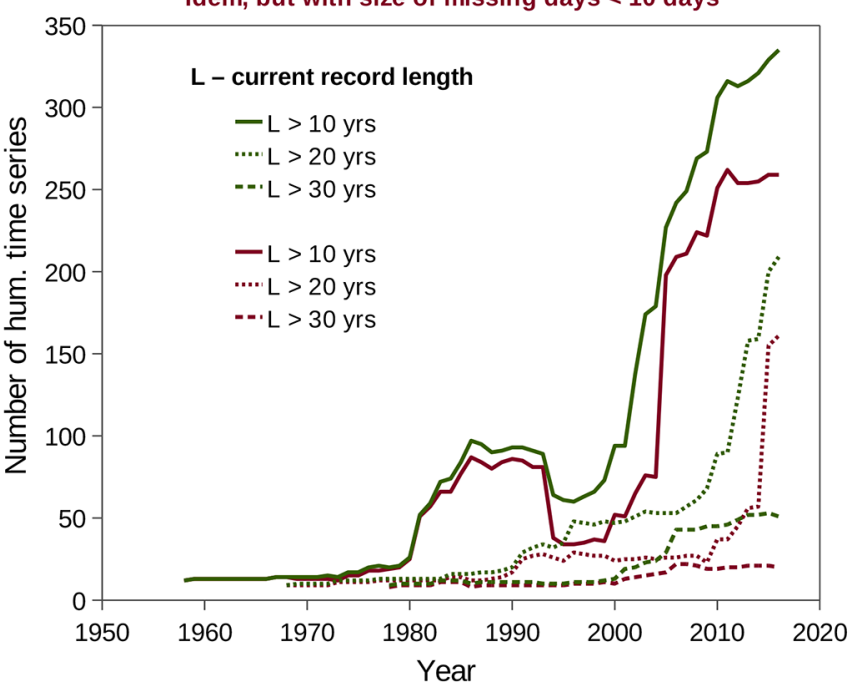

Figure 11. Number of humidity time series with a record length exceeding a given number of years until the year in abscissa (see insets), under different completeness criteria (indicated on top of the graphs).

ward or forward in time, can be derived from the information contained in the related metadataset (Sect. 4.1). In addition, the years with humidity observations can be found in Table S1 (as well as in a data file accompanying the two main metadatasets): one or more periods per station, depending on whether there are gap years or not in the station's full period of record.

\section{Metadatasets of completeness of radiosonde humidity observations based on the IGRA}

The metadatasets describing the completeness of radiosonde humidity records collected in the IGRA are outlined next. They are constructed upon the completeness measures introduced in Sect. 2.3 and examined in Sect. 3, except for minor adaptions described in the subsections below. The combination of selection criteria, by simply specifying value ranges for the metadata parameters, offers a plethora of choices to the user. Both sets refer to sounding data from the IGRA-RS subset of IGRA 2 stations, as defined in Sect. 2.2 and listed in Table S1, which essentially excludes pilot-balloon stations.

\subsection{Metadata by station and year}

The metadata parameters regarding each IGRA-RS station and year (annual statistics) are defined in Table 2. Since pressure is the vertical coordinate that is always present in humidity radiosonde data, and the calculation of height above mean sea level is impossible when the surface level is missing, the average vertical extent of humidity data at a given station and year is represented by the geometric mean value of the lowest pressure with humidity data. (Given the huge number of values involved, the arithmetic mean of the logarithm of pressure was calculated first and then exponentiated.) Note that the geometric mean pressure of the highest level with humidity data provides a natural measure of the corresponding arithmetic mean altitude: insomuch as pressure decreases almost exponentially with height, the arithmetic mean height above sea level is roughly proportional to the logarithm of the geometric mean pressure. The statistics for the vertical resolution of humidity data consist in the annual mean of the "mean vertical resolution" of individual soundings at each station, calculated by Eq. (2). The IGRA data meeting the definition of Sfc-to-500hPa humidity soundings as stated in Sect. 2.3.4 have their own metadata: number of observations, average vertical resolution, size of missing days, and fraction of days in a year having humidity data.

The metadataset is as a plain-text file, each data record containing the metadata values, station by station and year by year. For each station, the yearly variables defined in Table 2 are displayed chronologically. To put humidity metadata into context, the yearly number of soundings (including PIBAL) and of temperature observations (denoting RAOBs) are also given (not shown in Table 2). The years within a station's period of record with observations of any meteorological variable (wind, temperature, humidity) in IGRA are kept, using appropriate missing values when humidity data are missing throughout a whole year. While humidity data begin in 1930, pre-radiosonde years are included to preserve the stations' history.

The above metadataset is complemented by a list of the IGRA-RS stations with information on geographic coordinates (if fixed), name, and country, along with original metadata describing the periods of record for humidity and the 
Table 2. Parameters of humidity completeness for each IGRA-RS station and year.

\begin{tabular}{ll}
\hline Parameter & Description (statistics refer to a year within the period of record of the station) \\
\hline Hum-A & No. of soundings with humidity observations \\
Hum-B & No. of soundings with Sfc-to-500hPa humidity observations ${ }^{1}$ \\
RESa & Annual mean vertical resolution of humidity observations ${ }^{2}$ \\
RESb & Annual mean vertical resolution of Sfc-to500hPa humidity observations ${ }^{3}$ \\
TOPP & Annual geometric mean pressure of the highest level with humidity data \\
GAPa & Largest interval of days in the year for which humidity observations are missing \\
GAPb & Largest interval of days in the year for which Sfc-to-500hPa hum. obs. are missing \\
FDYa & Fraction of days in a year with humidity observations \\
FDYb & Fraction of days in a year with Sfc-to-500hPa humidity observations \\
\hline
\end{tabular}

${ }^{1}$ As defined in Sect. 2.3.4. ${ }^{2}$ Arithmetic mean of the mean vertical resolution given by Eq. (2). ${ }^{3}$ Calculated as RESa, but between the surface and $500 \mathrm{hPa}$.

corresponding number of observations. This is an ASCII version of Table S1, for computing purposes.

\subsection{Metadata by station, date, and time}

The metadata parameters regarding individual soundings at each IGRA-RS station are defined in Table 3. The highest reported level with humidity is quantified by both pressure and geopotential altitude (rounded to the nearest decameter and calculated whenever surface data are available). The utility of the corresponding metadataset is to allow a fine selection of humidity data, as a complement to a first selection based on the statistical parameters of Table 2. This metadataset is organized into one plain-text file per station and one data record per sounding. Below the headline, each record contains the date, nominal hour, and latitude and longitude of the balloon launch, followed by the related humidity metadata.

\section{Data availability}

A dataset combining the metadatasets described in Sect. 4 (Ferreira et al., 2018) is available on Zenodo, https://doi.org/10.5281/zenodo.1332686. The accompanying "Readme" file gives the necessary information about the data format and file contents. The update is planned to take place each time 2 full years have been completed in IGRA, starting in 2019 for the period 2017-2018.

\section{Summary and recommendations}

This work has studied the completeness of radiosonde humidity observations compiled in IGRA Version 2 (Durre et al., 2016, 2018) upon setting aside the IGRA stations with more than $95 \%$ pilot-balloon data in every year of their period of record until the end of 2016. The selected set (denoted IGRA-RS) retains virtually all RAOBs distributed by 1723 stations, including 1300 WMO stations, of which 178 and 16 are, respectively, current GUAN and GRUAN sites. The earliest humidity observations are from the 1930s, when the radiosonde era had begun, but the number of data is only significant after around 1945. Several parameters describing the completeness of humidity observations were defined and then examined in statistical terms, providing a global picture of humidity completeness in radiosonde observations over time. The main conclusions, for the years beginning in 1945, are as follows.

The radiosonde network providing humidity observations in the northern temperate and polar latitudes was essentially established in the mid-1950s. In the mid-1970 the globe became covered by practically the same number of humidityreporting fixed stations as it is today, although the distribution of stations has changed considerably over time. The averaged distance to the nearest station measured from points over continents and large islands (from Mindanao up to Greenland in size), ranging from $\sim 200 \mathrm{~km}$ in the northern midlatitude countries to $\sim 700 \mathrm{~km}$ in Antarctica, has changed little too. However, the spatial distribution of continental stations continues to show important regional disparities, such as the poor coverage of most of sub-Saharan Africa, which has worsened from the 1970s to the present. Concerning ocean/sea areas and disregarding mobile stations (mostly "ships of opportunity"), the oceans of the southern temperate latitudes always exhibit the poorest coverage, with an average distance to the nearest station exceeding $1000 \mathrm{~km}$. Remarkably, the shorter distances in the North Hemisphere oceans and seas extending from the subtropics to the Arctic have been increasing significantly during the past half century.

The fraction of days in a year with humidity observations greatly increased until 1960, on average calculated for each year across the stations in each of the main latitude regions. Since 1965 , the mean values are in the range of $70 \%-80 \%$ in low latitudes and $80 \%-95 \%$ in midlatitudes and high latitudes annually, although individual values vary widely among stations. Between 1945 and 1955, the size of missing days in humidity observations (largest gap in days) in each year having any humidity data decreased from about 5 months to 1 month on global average. After 1960, the size 
Table 3. Parameters of humidity completeness for each sounding.

\begin{tabular}{ll}
\hline Parameter & Description \\
\hline RAOB & $\begin{array}{l}\text { Classifies the sounding according to RAOB } \\
\\
0=\text { none (only wind data) } 1=\text { TEMP data, but missing HUM; }\end{array}$ \\
& $2=$ TEMP and HUM data; $3=$ TEMP and Sfc-to-500hPa HUM $\mathrm{HU}^{2}$ \\
RESa & Mean vertical resolution of humidity data values \\
RESb & Mean vertical resolution of Sfc-to-500hPa humidity data \\
TOPP & Atmospheric pressure of the highest level with humidity data \\
TOPZ & Altitude above mean sea level of the highest level with humidity data
\end{tabular}

${ }^{1}$ Pre-radiosonde obs. included. ${ }^{2}$ As defined in Sect. 2.3.4. ${ }^{3}$ Calculated by Eq. (2). ${ }^{4}$ Calculated as RESa, but between the surface and $500 \mathrm{hPa}$.

of missing days exhibits averages around $20 \mathrm{~d}$ in middle and high latitudes; in low latitudes it has increased over time from around 30 to $40 \mathrm{~d}$.

Humidity was measured mostly in the lower to middle troposphere until the mid-1960s. Since the mid-1980s, the mean height achieved by humidity measurements has increased by $\approx 4 \mathrm{~km}$ per decade on global average; the gap distance to the burst altitude (denoted by the maximum height of the temperature measurements) more than halved. At present, that gap is $\approx 5 \mathrm{~km}$ and three-quarters of the humidity soundings reach to at least $13 \mathrm{~km}$ in altitude. However, the dispersion of the maximum height of humidity data around the mean has increased too, likely due to the coexistence of older humidity sensors with new sensors. The vertical-mean resolution of humidity observations (geometric mean of the distance between consecutive levels with data) had a median in the range of $1.3-1.4 \mathrm{~km}$ until 1965 , among all humidity soundings in each year, with an interquartile range of $\approx 1 \mathrm{~km}$. Thereafter, the median and midspread improved a lot before stabilizing in the early 2000s; since then, half of the annual soundings present a vertical-mean resolution between 0.3 and $0.5 \mathrm{~km}$.

The number of stations providing Sfc-to-500hPa profiles with adequate resolution for calculating precipitable water vapor in more than $80 \%$ of the reported humidity soundings in a year has changed from a few dozen in the period 1945-1970 to around 800 in recent years (97\% of the active radiosonde stations by 2014/16). In general, the number of stations having a significant percentage of Sfc-to-500hPa observations shows a sudden increase around the years 1970, 1991/92, and 2000. These change points are associated with the availability of data at the surface level and at nonstandard near-surface levels; the latter provide important information in the planetary boundary layer before 1992, when the $925 \mathrm{hPa}$ level was not standard and was rarely used.

To conclude, the number of humidity time series with a given number of consecutive years of data until a given year depends not only on the year and the length of record, but also on other completeness criteria. For example, the stationbased time series extending back in time for at least 30 years and being $90 \%$ complete (in terms of fraction of days in a year) begin with a few units in 1977 and represent around 200 stations in recent years; by further requiring Sfc-to-500hPa completeness, the other criteria being the same, the maximum number of time series drops to 50 by 2016. If missing days are distributed among short-term data gaps, the time series are further restricted. Evidently, the equivalent time series until the same year but with a much shorter duration, e.g., 10 years as a minimum, are several times more numerous and start much earlier. In short, the number of humidity time series that are potentially available to perform climate studies, i.e., discounting accuracy requirements and biases due to instrument changes, depends strongly on the strictness of the completeness criteria.

Furthermore, this paper presents a dataset of completeness of radiosonde humidity observations (RH or DPD together with pressure and temperature) based on IGRA data for the IGRA-RS stations. The dataset (Ferreira et al., 2018) consists of (1) statistical metadata for each station and year, in a single file for the 1723 stations and their full period of record until 2016; (2) metadata specific to individual soundings, organized in one file per station and covering 39.5 million soundings in total; and (3) a list of stations along with the observing periods for humidity and the corresponding number of observations. The metadata parameters were designed to facilitate the selection of upper-air humidity data from IGRA according to a plethora of choices, therefore being able to meet specific research needs in the areas of atmospheric and environmental sciences.

It is widely known that the usefulness of historical radiosonde data depends crucially on metadata information about instrumentation and observing practices (Schwartz and Doswell, 1991; Elliot and Gaffen, 1991; Gaffen, 1996; Parker and Cox, 1995). However, sampling differences among stations associated with geographical coverage, observing periods, and missing data are no less important than differences in data precision and accuracy. Reporting practices related to limitations of humidity sensors particularly affect the humidity records (Garand et al., 1992; McCarthy et al., 2009). Therefore, the metadata presented in this paper, if used as a tool to find out the more complete humidity time series - relatively long, regular, and continuous as well as vertically extensive and well resolved - should be crossed with 
the station history metadata available in IGRA. Conversely, the present metadata might accelerate progress in the current research on the homogenization of radiosonde humidity data (McCarthy et al., 2009; Dai et al., 2011) by sampling stations with coincident observing periods and satisfying reasonable completeness criteria.

Supplement. The supplement related to this article is available online at: https://doi.org/10.5194/essd-11-603-2019-supplement.

Author contributions. APF designed the study and performed the data processing under supervision of LG and RN. APF prepared the first draft of the manuscript and all authors contributed to subsequent revisions.

Competing interests. The authors declare that they have no conflict of interest.

Acknowledgements. We thank Imke Durre for clarifying some points about IGRA Version 2 and David Carlson and the two anonymous reviewers for many helpful comments. We also thank Orlando García-Feal for IT support at EPhysLab (Environmental Physics Laboratory at the Faculty of Science of the University of Vigo, Ourense Campus). This work was funded by the Spanish government within the EVOCAR project (CGL2015-65141-R), cofunded by the European Regional Development Fund, and partially supported by the Galician regional government through the program Consolidation and Structuring of Competitive Research Units - Competitive Reference Groups (ED431C 2017/64-GRC).

Review statement. This paper was edited by David Carlson and reviewed by two anonymous referees.

\section{References}

Andersson, E., Hólm, E., Bauer, P., Beljaars, A., Kelly, G. A., McNally, A. P., Simmons, A. J., Thépaut, J., and Tompkins, A. M.: Analysis and forecast impact of the main humidity observing systems, Q. J. Roy. Meteor. Soc., 133, 1473-1485, https://doi.org/10.1002/qj.112, 2007.

Bellamy, J. C.: Some basic characteristics of observational data, in Meteorological Observations and Instrumentation - 1970, Proceedings of the American Meteorological Society Symposium on Meteorological Observations and Instrumentation, Washington, D. C., USA, 10-14 February 1969, https://doi.org/10.1007/9781-935704-35-5, 1970.

Bodeker, G. E., Bojinski, S., Cimini, D., Dirksen, R. J., Haeffelin, M., Hannigan, J. W., Hurst, D. F., Leblanc, T., Madonna, F., Maturilli, M., Mikalsen, A. C., Philipona, R., Reale, T., Seidel, D. J., Tan, D. G. H., Thorne, P. W., Vömel, H., and Wang, J.: Reference Upper-Air Observations for Climate:
From Concept to Reality, B. Am. Meteorol. Soc., 97, 123-135, https://doi.org/10.1175/BAMS-D-14-00072.1, 2016.

Brettle, M. J. and Galvin, J. F. P.: Back to basics: Radiosondes: Part 1 - The instrument, Weather, 58, 336-341, https://doi.org/10.1256/wea.126.02A, 2003.

Connell, B. H. and Miller, D. R.: An interpretation of radiosonde errors in the atmospheric boundary layer, $\mathrm{J}$. Appl. Meteorol., 34, 1070-1081, https://doi.org/10.1175/15200450(1995)034<1070:AIOREI>2.0.CO;2, 1995.

Dabberdt, W. F., Cole, H., Paukkunen, A., Horhammer, J., Antikainen, V., and Shellhorn, R.: Radiosondes, in: Encyclopedia of Atmospheric Sciences, Vol. 6, edited by: By Holton, J. R., Pyle, J., and Curry, J. A., Elsevier Science/Academic Press, Amsterdam, the Netherlands, 2002, 1900-1913, 2002.

Dai, A., Wang, J, Thorne, P. W., Parker, D. E., Haimberger, L., and Wang, X. L.: A new approach to homogenize radiosonde humidity data, J. Climate, 24, 965-991, https://doi.org/10.1175/2010JCLI3816.1, 2011.

Dirksen, R. J., Sommer, M., Immler, F. J., Hurst, D. F., Kivi, R., and Vömel, H.: Reference quality upper-air measurements: GRUAN data processing for the Vaisala RS92 radiosonde, Atmos. Meas. Tech., 7, 4463-4490, https://doi.org/10.5194/amt-7-4463-2014, 2014.

Driemel, A., Loose, B., Grobe, H., Sieger, R., and KönigLanglo, G.: 30 years of upper air soundings on board of R/V POLARSTERN, Earth Syst. Sci. Data, 8, 213-220, https://doi.org/10.5194/essd-8-213-2016, 2016.

DuBois, J. L., Multhauf, R. P., and Ziegler, C. A.: The Invention and Development of the Radiosonde, Smithsonian Institution Press, Washington, D.C., USA, 78 pp., 2002.

Durre, I.: Integrated Global Radiosonde Archive V2, Dataset Description, Version 1.0, 15 pp., available at: https://www1.ncdc. noaa.gov/pub/data/igra (last access: September 2017), 2016.

Durre, I., Reale, T., Carlson, D., Christy, J., Uddstrom, M., Gelman, M., and Thorne, P.: Improving the usefulness of operational radiosonde data, B. Am. Meteorol. Soc., 86, 411-418, https://doi.org/10.1175/BAMS-86-3-411, 2005.

Durre, I., Vose, R. S., and Wuertz, D. B.: Overview of the Integrated Global Radiosonde Archive, J. Climate, 19, 53-68, https://doi.org/10.1175/JCLI3594.1, 2006.

Durre, I., Williams Jr., C. N., Yin, X., and Vose, R. S.: Radiosonde-based trends in precipitable water over the Northern Hemisphere: An update, J. Geophys. Res., 114, D05112, https://doi.org/10.1029/2008JD010989, 2009.

Durre, I., Vose, R. S., Yin, X., Applequist, S., and Arnfield, J: Integrated Global Radiosonde Archive (IGRA) Version 2, full period-of-record (POR) data, NOAA National Centers for Environmental Information, https://doi.org/10.7289/v5x63k0q, 2016.

Durre, I., Yin, X., Vose, R. S., Applequist, S., and Arnfield, $\mathrm{J}$.: Enhancing the data coverage in the Integrated Global Radiosonde Archive, J. Atmos. Ocean. Tech., 35, 1753-1770, https://doi.org/10.1175/JTECH-D-17-0223.1, 2018.

Elliott, W. P. and Gaffen, D. J.: On the utility of radiosonde humidity archives for climate studies, B. Am. Meteorol. Soc., 72, 1507-1520, https://doi.org/10.1175/15200477(1991)072<1507:OTUORH>2.0.CO;2, 1991.

Elliott, W. P., Smith, M. E, Angell, J. K.: Monitoring tropospheric water vapor changes using radiosonde data, edited by: Schlesinger, M. E., Developments in Atmospheric Sci- 
ence, Elsevier, Amsterdam, the Netherlands, vol. 19, 311-327, https://doi.org/10.1016/B978-0-444-88351-3.50027-1, 1991.

Elms, J.: WMO catalogue of radiosondes and upper-air wind systems in use by members in 2002, Report No. 80, WMO/TD No. 1197, Part A, available at: https://library.wmo.int (last access: 11 April 2018), 2003.

Eskridge, R. E., Alduchov, O. A., Chernykh, I. V., Panmao, Z., Polansky, A. C., and Doty, S.: A Comprehensive Aerological Reference Data Set (CARDS): Rough and systematic errors, B. Am. Meteorol. Soc., 76, 1759-1775, https://doi.org/10.1175/15200477(1995)076<1759:ACARDS>2.0.CO;2, 1995.

Ferreira, A. P., Nieto, R., and Gimeno, L.: A dataset of completeness of radiosonde humidity observations based on the IGRA [Data set], Zenodo, https://doi.org/10.5281/zenodo.1332686, 2018.

Free, M. and Seidel, D. J.: Causes of differing temperature trends in radiosonde upper air data sets, J. Geophys. Res., 110, D07101, https://doi.org/10.1029/2004JD005481, 2005.

Gaffen, D. J.: Historical Changes in Radiosonde Instruments and Practices, IOM Report No. 50, WMO/TD-No. 541, 128 pp., available at: https://library.wmo.int (last access: 15 March 2018), 1993.

Gaffen, D. J.: A Digitized Metadata Set of Global Upper-Air Station Histories, NOAA Technical Memorandum ERL ARL-211, Silver Spring, MD, 38 pp., available at: ftp://ftp.ncdc.noaa.gov/ pub/data/images/gaffen 1996.pdf (last access: 22 February 2018), 1996.

Gaffen, D. J., Barnett, T. P., and Elliott, W. P.: Space and time scales of global tropospheric moisture, J. Climate, 4, 989-1008, https://doi.org/10.1175/15200442(1991)004<0989:SATSOG>2.0.CO;2, 1991.

Gaffen, D. J., Robock, A., and Elliott, W. P.: Annual cycles of tropospheric water vapor, J. Geophys. Res., 97, 18185-18193, https://doi.org/10.1029/92JD01999, 1992.

Garand, L., Grassotti, C., Hall, J., and Klein, G. L.: On differences in radiosonde humidity-reporting practices and their implications for numerical weather prediction and remote sensing, B. Am. Meteorol. Soc., 73, 1417-1423, https://doi.org/10.1175/15200477(1992)073<1417:ODIRHR>2.0.CO;2, 1992.

Gutnick, M.: Mean Annual Mid-Latitude Moisture Profiles to 31 km, Air Force Research Report, AFCRL-62-681, July 1962, available at: http://www.dtic.mil/dtic/tr/fulltext/u2/286147.pdf (last access: 23 March 2018), 1962.

Haimberger, L., Tavolato, C, and Sperka, S: Toward elimination of the warm bias in historic radiosonde temperature records - Some new results from a comprehensive intercomparison of upper-air data, J. Climate, 21, 4587-4606, https://doi.org/10.1175/2008JCLI1929.1, 2008.

Hall, E. G., Jordan, A. F., Hurst, D. F., Oltmans, S. J., Vömel, H., Kühnreich, B., and Ebert, V.: Advancements, measurement uncertainties, and recent comparisons of the NOAA frost point hygrometer, Atmos. Meas. Tech., 9, 4295-4310, https://doi.org/10.5194/amt-9-4295-2016, 2016.

Hartten, L. M., Cox, C. J., Johnston, P. E., Wolfe, D. E., Abbott, S., McColl, H. A., Quan, X.-W., and Winterkorn, M. G.: Ship- and island-based soundings from the 2016 El Niño Rapid Response (ENRR) field campaign, Earth Syst. Sci. Data, 10, 1165-1183, https://doi.org/10.5194/essd-10-1165-2018, 2018.
Hawson, C. L.: Performance requirements of aerological instruments, WMO Tech. Note 112, WMO 267, 49 pp., available at: https://library.wmo.int (last access: 28 December 2017), 1970.

Hickman, A.: History of pilot ballooning, Weather, 70, S21-S23, https://doi.org/10.1002/wea.2526, 2015.

Hurst, D. F., Hall, E. G., Jordan, A. F., Miloshevich, L. M., Whiteman, D. N., Leblanc, T., Walsh, D., Vömel, H., and Oltmans, S. J.: Comparisons of temperature, pressure and humidity measurements by balloon-borne radiosondes and frost point hygrometers during MOHAVE-2009, Atmos. Meas. Tech., 4, 2777-2793, https://doi.org/10.5194/amt-4-2777-2011, 2011.

Ingleby, B.: An Assessment of Different Radiosonde Types 2015/2016, ECMWF Technical Memorandum No. 807, European Centre for Medium Range Weather Forecasts, Reading, UK, available at: http://www.gaia-clim.eu/system/files/publications/ 17551-assessment-different-radiosonde-types-20152016.pdf (last access: 7 January 2019), 2017.

Ingleby, B., Pauley, P., Kats, A., Ator, J., Keyser, D., Doerenbecher, A., Fucile, E., Hasegawa, J., Toyoda, E., Kleinert, T., Qu, W., St. James, J., Tennant, W., and Weedon, R.: Progress toward high-resolution, real-time radiosonde reports, B. Am. Meteorol. Soc., 97, 2149-2161, https://doi.org/10.1175/BAMS-D-15$00169.1,2016$.

John, V. O. and Buehler, S. A.: Comparison of microwave satellite humidity data and radiosonde profiles: A survey of European stations, Atmos. Chem. Phys., 5, 1843-1853, https://doi.org/10.5194/acp-5-1843-2005, 2005.

Karl, T. F., Derr, V. E., Easterling, D. R., Folland, C. K., Hofmann, D. J., Levitus, S., Nicholls, N., Parker, D. E., and Withee, G. W.: Critical issues for long-term climate monitoring, Climatic Change, 31, 185-221, https://doi.org/10.1007/BF01095146, 1995.

Kishore, P., Venkat Ratnam, M., Namboothiri, S. P., Velicogna, I., Basha, G., Jiang, J. H., Igarashi, K., Rao, S. V. B., and Sivakumar, V.: 2011. Global $\left(50^{\circ} \mathrm{S}-50^{\circ} \mathrm{N}\right)$ distribution of water vapor observed by COSMIC GPS RO: Comparison with GPS radiosonde, NCEP, ERA-Interim, and JRA-25 reanalysis data sets, J. Amos. Sol.-Terr. Phy., 73, 1849-1860, https://doi.org/10.1016/j.jastp.2011.04.017, 2011.

Kitchen, M.: Compatibility of radiosonde geopotential measurements, IOM Report No. 36, WMO/TD No. 344, available at: https://library.wmo.int (last access: 15 March 2018), 1989a.

Kitchen, M.: Representativeness errors for radiosonde observations, Q. J. Roy. Meteor. Soc., 115, 673-700, https://doi.org/10.1002/qj.49711548713, 1989b.

Kley, D., Russell, J. M., and Phillips, C.: SPARC assessment of upper tropospheric and stratospheric water vapour, WCRP- No. 113, WMO/TD - No. 1043, SPARC Report No. 2, available at: https://library.wmo.int (last access: 9 September 2017), 2000.

Kuo, Y.-H., Schreiner, W. S., Wang, J., Rossiter, D. L., and Zhang, Y.: Comparison of GPS radio occultation soundings with radiosondes, Geophys. Res. Lett., 32, L05817, https://doi.org/10.1029/2004GL021443, 2005.

Lanzante, J. R., Klein, S. A., and Seidel, D. J.: Temporal homogenization of monthly radiosonde temperature data. Part I: Methodology, J. Climate, 16, 224-240, https://doi.org/10.1175/15200442(2003)016<0224:THOMRT>2.0.CO;2, 2003. 
Laroche, S. and Sarrazin, R.: Impact of Radiosonde Balloon Drift on Numerical Weather Prediction and Verification, Weather Forecast., 28, 772-782, https://doi.org/10.1175/WAFD-12-00114.1, 2013.

Luers, J. K. and Eskridge, R. E.: Use of radiosonde temperature data in climate studies, J. Climate, $11, \quad 1002-1019$, https://doi.org/10.1175/15200442(1998)011<1002:UORTDI>2.0.CO;2, 1998.

Mastenbrook, H. J. and Daniels, R. E.: Measurements of stratospheric water vapor using a frost-point hygrometer, in: Atmospheric water vapor, edited by: Deepak, A., Wilkerson, T. D., and Ruhnke, L. H., Academic Press, New York, USA, 329-342, 1980.

McCarthy, M. P.: Spatial sampling requirements for monitoring upper-air climate change with radiosondes, Int. J. Climatol., 28, 985-993, https://doi.org/10.1002/joc.1611, 2008.

McCarthy, M. P., Thorne, P. W., and Titchner, H. A.: An analysis of tropospheric humidity trends from radiosondes. J. Climate, 22, 5820-5838, https://doi.org/10.1175/2009JCLI2879.1, 2009.

McGrath, R., Semmler, T., Sweeney, C., and Wang, S.: Impact of balloon drift errors in radiosonde data on climate statistics, J. Climate, 19, 3430-3442, https://doi.org/10.1175/JCLI3804.1, 2006.

Miloshevich, L. M., Vömel, H., Whiteman, D. N., Lesht, B. M., Schmidlin, F. J., and Russo, F.: Absolute accuracy of water vapor measurements from six operational radiosonde types launched during AWEX-G and implications for AIRS validation, J. Geophys. Res., 111, D09S10, https://doi.org/10.1029/2005JD006083, 2006.

Moradi, I., Soden, B., Ferraro, R., Arkin, P., and Vömel, H.: Assessing the quality of humidity measurements from global operational radiosonde sensors, J. Geophys. Res.-Atmos., 118, 80408053, https://doi.org/10.1002/jgrd.50589, 2013.

Nash J.: Review of test results on the accuracy of radiosonde relative humidity sensors, in: Proc. ECMWF/GEWEX Workshop on Humidity analysis, Reading, UK, 8-11 July 2002, 117-123, 2002.

Nash, J.: Measurement of upper-air pressure, temperature and humidity, IOM Report No. 121, World Meteorological Organization, available at: https://library.wmo.int (last access: 22 December 2017), 2015.

Nash, J., Gaffard, C., Smout, R., and Smees, M.: Introduction to upper-air measurements with radiosondes and other in-situ observing systems, Observation Development, Met Office, Exeter, 3-7 September 2007, L'Aquila, Italy, available at: https://www.wmo.int/pages/prog/www/IMOP/meetings/ Upper-Air/ET-IOC-3/Doc3.1(1).pdf (last access: 1 April 2019), 2007.

Nash, J., Oakley, T., Vömel, H., and Wei, L. I.: WMO intercomparison of high quality radiosonde systems (Yangjiang, China 12 June-3 August 2010), WMO Instruments and Observing Methods Rep. 107, 238 pp., available at: http://www.wmo.int/ (last access: 28 December 2018), 2011.

Noh, Y.-C., Sohn, B.-J., Kim, Y., Joo, S., and Bell, W: Evaluation of temperature and humidity profiles of Unified Model and ECMWF analyses using GRUAN radiosonde observations, Atmosphere, 7, 94, https://doi.org/10.3390/atmos7070094, 2016.

Oakley, T: Report by the Rapporteur on Radiosonde Compatibility Monitoring. Part B - Compatibility of Radiosonde Geopotential Measurements 1990, 1991 and 1992. IOM Report No. 56,
WMO/TD No. 587, available at: https://library.wmo.int (last access: 1 May 2018), 1993.

OFCM - Office of the Federal Coordinator for Meteorology: Federal Meteorological Handbook No. 3 - Rawinsonde and pibal observations, National Oceanic and Atmospheric Administration, Washington, D.C., USA, available at: https://www.ofcm. gov/publications/fmh/allfmh2.htm (last access: 23 March 2018), 1997.

Parker, D. E. and Cox, D. I.: Towards a consistent global climatological rawinsonde data-base, Int. J. Climatol., 15, 473-496, https://doi.org/10.1002/joc.3370150502, 1995.

Rieckh, T., Anthes, R., Randel, W., Ho, S.-P., and Foelsche, U.: Evaluating tropospheric humidity from GPS radio occultation, radiosonde, and AIRS from high-resolution time series, Atmos. Meas. Tech., 11, 3091-3109, https://doi.org/10.5194/amt11-3091-2018, 2018.

Ross, R. J. and Elliott, W. P.: Tropospheric water vapor climatology and trends over North America: 197393, J. Climate, 9, 3561-3574, https://doi.org/10.1175/15200442(1996)009<3561:TWVCAT>2.0.CO;2, 1996.

Ross, R. J. and Elliott, W. P.: Radiosonde-based Northern Hemisphere tropospheric water vapor trends, J. Climate, 14, 1602-1611, https://doi.org/10.1175/15200442(2001)014<1602:RBNHTW>2.0.CO;2, 2001.

Sapucci, L.F., Machado, L. A., da Silveira, R. B., Fisch, G., and Monico, J. F.: Analysis of relative humidity sensors at the WMO Radiosonde Intercomparison Experiment in Brazil, J. Atmos. Ocean. Tech., 22, 664-678, https://doi.org/10.1175/JTECH1754.1, 2005.

Schwartz, B. E. and Doswell, C. A.: North American rawinsonde observations: Problems, concerns, and a call to action, B. Am. Meteorol. Soc., 72, 1885-1896, https://doi.org/10.1175/15200477(1991)072<1885:NAROPC>2.0.CO;2, 1991.

Seidel, D. J., Ao, C. O., and Li, K.: Estimating climatological planetary boundary layer heights from radiosonde observations: Comparison of methods and uncertainty analysis, J. Geophys. Res., 115, D16113, https://doi.org/10.1029/2009JD013680, 2010.

Seidel, D. J., Sun, B., Pettey, M., and Reale, A.: Global radiosonde balloon drift statistics, J. Geophys. Res., 116, D07102, https://doi.org/10.1029/2010JD014891, 2011.

Shangguan, M., Matthes, K., Wang, W., and Wee, T.-K.: Validation of COSMIC water vapor data in the upper troposphere and lower stratosphere using MLS, MERRA and ERA-Interim, Atmos. Meas. Tech. Discuss., https://doi.org/10.5194/amt-2016248, in review, 2016.

Shea, D. J., Worley, S. J, Stern, I. R. and Hoar, T. J.: An introduction to atmospheric and oceanographic data, National Center for Atmospheric Research, Tech. Note 404, 136 pp., available at: https://library.ucar.edu/ (last access: 14 March 2018), 1994.

Smit, H., Kivi, R., Vömel, H., and Paukkunen, A.: Thin film capacitive sensors, in Monitoring Atmospheric Water Vapour Ground-Based - Remote Sensing and In-situ Methods, ISSI Scientific Report No 10, edited by: Kämpfer, N., Springer, https://doi.org/10.1007/978-1-4614-3909-7, 2013

Soden, B. and Lanzante, J.: An assessment of satellite and radiosonde climatologies of upper-tropospheric water vapor, J. Climate, 9, 1235-1250, https://doi.org/10.1175/15200442(1996)009<1235:AAOSAR>2.0.CO;2, 1996. 
Stickler, A., Grant, A. N., Ewen, T., Ross, T. F., Vose, R. S., Comeaux, J., Bessemoulin, P., Jylhä, K., Adam, W. K., Jeannet, P. Nagurny, A. Sterin, A. M. Allan, R., Compo, G. P. Griesser, T., and Brönnimann, S.: The Comprehensive Historical Upper Air Network (CHUAN), B. Am. Meteorol. Soc., 91, 741-751, https://doi.org/10.1175/2009BAMS2852.1, 2010.

Sugita, M. and Brutsaert, W.: Daily evaporation over a region from lower boundary layer profiles measured with radiosondes, Water Resour. Res., 27, 747-752, https://doi.org/10.1029/90WR02706, 1991.

Sun, B., Reale, A., Seidel, D. J., and Hunt, D. C.: Comparing radiosonde and COSMIC atmospheric profile data to quantify differences among radiosonde types and the effects of imperfect collocation on comparison statistics, J. Geophys. Res., 115, D23104, https://doi.org/10.1029/2010JD014457, 2010.

Thorne, P. W., Parker, D. E., Tett, S. F. B., Jones, P. D., McCarthy, M. Coleman, H., and Brohan P.: Revisiting radiosonde upper air temperatures from 1958 to 2002, J. Geophys. Res., 110, D18105, https://doi.org/10.1029/2004JD005753, 2005.

Vergados, P., Mannucci, A. J., Ao, C. O., Verkhoglyadova, O., and Iijima, B.: Comparisons of the tropospheric specific humidity from GPS radio occultations with ERA-Interim, NASA MERRA, and AIRS data, Atmos. Meas. Tech., 11, 1193-1206, https://doi.org/10.5194/amt-11-1193-2018, 2018.

Vömel, H., David, D. E., and Smith, K.: Accuracy of tropospheric and stratospheric water vapor measurements by the cryogenic frost point hygrometer (CFH): Instrumental details and observations, J. Geophys. Res., 112, D08305, https://doi.org/10.1029/2006JD007224, 2007.

Wade, C. G.: An evaluation of problems affecting the measurement of low relative humidity on the United States radiosonde, J. Atmos. Ocean. Tech., 11, 687-700, https://doi.org/10.1175/15200426(1994)011<0687:AEOPAT>2.0.CO;2, 1994.

Wallis, T. W.: A subset of core stations from the Comprehensive Aerological Reference Dataset (CARDS), J. Climate, 11, 272-282, https://doi.org/10.1175/15200442(1998)011<0272:ASOCSF>2.0.CO;2, 1998.

Wang, J., Cole, H. L., Carlson, D. J., Miller, E. R., Beierle, K., Paukkunen, A., and Laine, T. K.: Corrections of Humidity Measurement Errors from the Vaisala RS80 Radiosonde - Application to TOGA COARE Data, J. Atmos. Ocean. Tech., 19, 981-1002, https://doi.org/10.1175/15200426(2002)019<0981:COHMEF>2.0.CO;2, 2002.

Wang, J., Carlson, D. J., Parsons, D. B., Hock, T. F., Lauritsen, D., Cole, H. L., Beierle, K., and E. Chamberlain, E.: Performance of operational radiosonde humidity sensors in direct comparison with a chilled mirror dew-point hygrometer and its climate implication, Geophys. Res. Lett., 30, 1860, https://doi.org/10.1029/2003GL016985, 2003.

Wenstrom, W. H.: On pilot balloons and sources of light for high altitude upper-wind observations, Mon. Weather. Rev., 65, 326-331, https://doi.org/10.1175/15200493(1937)65<326:OPBASO>2.0.CO;2, 1937.
WMO: Meteorology - A three-dimensional science: Second session of the commission for aerology, in WMO Bull., IV, (4), 134-138, available at: https://library.wmo.int (last access: 15 March 2018), 1957.

WMO: Commission for Synoptic Meteorology, Abridged Final Report of the Second Session, New-Delhi, 21 January-15 February 1958, WMO-No. 74, RP. 30, available at: https://library.wmo.int (last access: 14 March 2018), 1958.

WMO: Commission for Synoptic Meteorology, Abridged Final Report of the Second Session, Geneva, 15 June-3 July 1970, WMO-No. 269, RP. 86, available at: https://library.wmo.int (last access: 16 March 2018), 1970.

WMO: Twenty-Ninth Session of the Executive Committee, Abridged Report with Resolutions, Geneva, 26 May-15 June 1977, WMO-No. 483, available at: https://library.wmo.int (last access: 14 March 2018), 1977.

WMO: Thirty-Ninth Session of the Executive Council, Abridged Report with Resolutions, Geneva, 1-5 June 1987, WMO - No. 682, available at: https://library.wmo.int (last access: 14 March 2018), 1987.

WMO: WMO Manual on Codes, vol. I., World Meteorological Organization, Geneva, Switzerland, 1988.

WMO: Calculation of Monthly and Annual 30-Year Standard Normals, WCDP-No. 10, WMO-TD/No. 341, available at: https: //library.wmo.int (last access: 25 June 2018), 1989.

WMO: Radiosonde humidity sensor intercomparison, Phase II Field Test, Laboratory for Hydrospheric Processes, Goddard Space Flight Center, Wallops Flight Facility, Wallops island, Virginia, USA, 8-26 September 1995, , available at: https://wmo.int (last access: 1 April 2019), 1995.

WMO: Guide to Meteorological Instruments and Methods of Observation, 6th edn., WMO Rep. 8, World Meteorological Organization, Geneva, Switzerland, 1996.

WMO: Guide to the GCOS Surface and Upper-Air Networks: GSN and GUAN, WMO/TD No. 1106, available at: https://library. wmo.int (last access: 22 February 2018), 2002.

WMO: Report of the Third GCOS Reference Upper Air Network Implementation and Coordination Meeting (GRUAN ICM-3), WMO/TD No. 1575, available at: https://library.wmo.int (last access: 17 September 2018), 2011a.

WMO: Guide to climatological practices, WMO No. 100., 2011 edition, World Meteorological Organization, Geneva, available at: http://www.wmo.int/ (last access: 17 September 2018), 2011b.

Zaitseva, N. A.: Historical developments in radiosonde systems in the former Soviet Union. B. Am. Meteorol. Soc., 74, 1893-1900, https://doi.org/10.1175/15200477(1993)074<1893:HDIRSI>2.0.CO;2, 1993.

Zhai, P. and Eskridge, R. E.: Atmospheric water vapor over China. J. Climate, 10, 2643-2652, https://doi.org/10.1175/15200442(1997)010<2643:AWVOC>2.0.CO;2, 1997. 